\title{
Big data analytics and organizational culture as complements to swift trust and collaborative performance in the humanitarian supply chain
}

\author{
Rameshwar Dubey ${ }^{\mathrm{a}}$, Angappa Gunasekaran ${ }^{\mathrm{b}, *}$, Stephen J. Childe ${ }^{\mathrm{c}}$, David Roubaud ${ }^{\mathrm{a}}$, \\ Samuel Fosso Wamba ${ }^{\mathrm{d}}$, Mihalis Giannakis ${ }^{\mathrm{e}}$, Cyril Foropon ${ }^{\mathrm{a}}$ \\ ${ }^{a}$ Montpellier Business School, Montpellier Research in Management, 2300 Avenue des Moulins, 34185 Montpellier, France \\ ${ }^{b}$ School of Business and Public Administration, California State University, Bakersfield, 9001 Stockdale Highway, Bakersfield, CA 93311-1022, USA

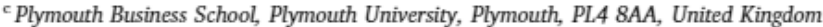 \\ ${ }^{\mathrm{d}}$ Toulouse Business School, Toulouse University, 20 Boulevard Lascrosses, 31068 Toulouse, France \\ ${ }^{\mathrm{e}}$ Audencia Business School, 8 route de la Joneliere-B.P. 31222, 44312 Nantes Cedex 3, France
}

A R T I C L E I N F O

\section{Keywords:}

Visibility

Big data and predictive analytics

Trust

Collaborative performance

Organizational culture

Multi-level confirmatory factor analysis

\begin{abstract}
A B S T R A C T
The main objective of the study is to understand how big data analytics capability (BDAC) as an organizational culture can enhance trust and collaborative performance between civil and military organizations engaged in disaster relief operations. The theoretical framework is grounded in organizational information processing theory (OIPT). We have conceptualized an original theoretical model to show, using the competing value model (CVM), how BDAC, under a moderating influence of organizational culture, affects swift trust (ST) and collaborative performance (CP). We used WarpPLS 6.0 to test the proposed research hypotheses using multi-respondent data gathered through an email questionnaire sent to managers working in 373 organizations, including the military forces of different countries, government aid agencies, UN specialized agencies, international non-government organizations (NGOs), service providers, and contractors. The results offer four important implications. First, BDAC has a positive, significant effect on ST and CP. Second, flexible orientation (FO) and controlled orientation (CO) have no significant influence on building ST. Third, FO has a positive and significant moderating effect on the path joining BDAC and CP. Finally, CO has negative and significant moderating effect on the path joining BDAC and CP. The control variables: temporal orientation (TO) and interdependency (I) have significant effects on ST and CP. These results extend OIPT to create a better understanding of the application of information processing capabilities to build swift trust and improve collaborative performance. Furthermore, managers can derive multiple insights from this theoretically-grounded study to understand how BDAC can be exploited to gain insights in contexts of different management styles and cultures. We have also outlined the study limitations and provided numerous future research directions.
\end{abstract}

\section{Introduction}

As the severity and frequency of large-scale natural disasters increases (Oloruntoba, 2010; Tatham and Rietjens, 2016; Jabbour et al., 2017), national and international disaster relief agencies are under extreme pressure to prepare for and respond to emergencies (Gillmann, 2009; International Peace Institute, 2013; Dwivedi et al., 2017). The civil-military exchange holds great promise for easing human suffering. The military provide unmatched security, logistical support, and rapid planning, while civil organizations offer financial support and volunteers to help with manual labor (Heaslip et al., 2008). Hence, disaster relief operations cannot achieve their desired success without effective and efficient coordination between civil and military groups. The lack of coordination and collaboration among supply chain actors or organizations results in poor response to disasters affected areas and major financial and life loss.

Moshtari (2016) argues that to address these challenges, donors and governments should build collaborative relationships between humanitarian organizations through exchanging information, knowledge, and resources. In literature, the terms "coordination" and "collaboration" are often used interchangeably. However, for the purposes of this study coordination is limited to the sharing of information and

\footnotetext{
* Corresponding author.

E-mail addresses: r.dubey@montpellier-bs.com (R. Dubey), agunasekaran@csub.edu (A. Gunasekaran), stephen.childe@plymouth.ac.uk (S.J. Childe), d.roubaud@montpellier-bs.com (D. Roubaud), s.fosso-wamba@tbs-education.fr (S. Fosso Wamba), mgiannakis@audencia.com (M. Giannakis), c.foropon@montpellier-bs.com (C. Foropon).
} 
resources, whereas collaboration is more concerned about working together to create something new (Balakrishnan and Geunes, 2004; Ergun et al., 2014; de Camargo et al., 2017). Hence, in this study we focus on the need for "collaboration" among organizations in the humanitarian supply chain.

Collaboration between actors can occur over one or more tasks, such as information sharing, capacity analysis, needs assessment, resource mobilization, procurement, transportation, warehousing, or last-mile delivery within the humanitarian supply chain (Moshtari, 2016; Oloruntoba et al., 2016). Scholars note that despite increasing collaboration, humanitarian organizations face significant challenges stemming from cultural and structural differences (see, Pettit and Beresford, 2009; Barber, 2011; Heaslip, 2011; Davis et al., 2013; Heaslip and Barber, 2014). In addition, each actor has its own resources, networks, and working experience. Ergun et al. (2014) note that coordination and collaboration in the humanitarian setting is complex due to difficult operational circumstances; many organizations function based on their own systems and objectives while working to contribute to the overall humanitarian cause.

The earthquakes in Haiti in 2010 and Nepal in 2015 provide concrete evidence concerning the role of technology and collaboration in disaster relief operations (Ergun et al., 2014; Papadopoulos et al., 2017; Singh et al., 2017). Even before earthquakes hit, hundreds of nongovernmental organizations (NGOs) and military organizations had developed their plans of action. Coordination after the disaster remained, as these small countries were flooded with thousands of organizations, well-meaning volunteers, and donors (Ergun et al., 2014). Nelson et al. (2010) point out that technologies such as mobile texting, interactive maps, crowdsourcing, and social media were used to locate and rescue survivors trapped in debris.

Wentz (2006) agrees that information and communication technologies (ICTs) were vital to the rescue efforts following the crises. Ergun et al. (2014) note that ICTs also served as crucial collaboration mechanisms for humanitarian organizations as they assisted the local government. Wentz (2006) argues that both civilian and military organizations need to understand ICTs' capabilities, so that relief and reconstruction efforts are better designed and coordinated by all actors working in the interest of the disaster victims. Many opportunities and challenges associated with coordination and collaboration among NGOs, military, governments and donors are highlighted in the literature (see Balcik et al., 2010; Tatham and Kovács, 2010; Ergun et al., 2014; Altay and Pal, 2014) focusing on technology-enabled collaboration, particularly between NGOs and the military. Ergun et al. (2014) and Dubey et al. (2018a) attempt to provide empirical evidence, but both of these studies focused on organizations at a similar level in the supply chain, such as NGOs delivering services or last-mile delivery, and not including co-ordinating organizations or armed forces. On the other hand, Ergun et al. (2014), explore conditions under which multiagency coordination is feasible using the cooperative game theory model.

Overall, literature has predominantly focused on IT capabilities, with interesting results (see, Yates and Paquette, 2011; Ragini et al., 2018). However, it appears necessary to identify and explore more specifically the effect of big data, which may be contrasted from one domain to another. With big data growing rapidly in importance, how to incorporate the advances provided by these technologies remains challenging, but highly promising. So far, the emphasis has been on the technical aspects, but it is important to understand the broader mechanisms through which big data may create value, including the organizational and cultural dimensions. Dubey et al. (2018a) empirically test how the use of big data and predictive analytics (BDPA) capability, can help improve visibility and coordination.

The need to understand how big data analytics (BDA) enables trust and collaboration among humanitarian organizations (i.e., civil and military), motivates the current study. We note that Big Data, BDA, and BDA capability are often used interchangeably in the literature (Fosso
Wamba et al., 2015). However, this study accounts for their theoretical differences in perspective, perception and measure. In this study, we present a theory-grounded investigation of the roles of BDA capability and organizational culture in the development of trust and the execution of analytics-based collaboration between civil and military organizations engaged in disaster relief operations. We use findings presented in existing studies (Galbraith, 1974, 1977; Altay and Pal, 2014; Srinivasan and Swink, 2015, 2018; Fan et al., 2017; Zhu et al., 2018) on how lateral relations (i.e. between operators or organizations working together or in parallel) and vertical information systems (i.e. overview, direction and supervision) can enhance information-processing capabilities (Peng et al., 2014), which may lead to superior coordination (Altay and Pal, 2014) and improved operational performance (Peng et al., 2014; Srinivasan and Swink, 2018). The lateral relationship among actors involved in disaster relief operations can increase availability of current and valuable information (Altay and Pal, 2014; Moshtari, 2016; Srinivasan and Swink, 2018). Peng et al. (2014) argue that vertical information systems allow organizations to process data to extract useful insights, which may help organizations to adjust or make new plans.

The existing literature conceptualizes BDA as a technologically-enabled organizational capability that can quickly process large volumes of various data to gain valuable insights (Fosso Wamba et al., 2015; Akter et al., 2016; Gupta and George, 2016), thereby enabling organizations to have a competitive advantage (Akter et al., 2016; Srinivasan and Swink. 2018; Dubey et al., 2018b). From an organizational information processing perspective (see Galbraith, 2014; Srinivasan and Swink, 2018; Gölzer and Fritzsche, 2017), we argue that this capability is both a challenge and an opportunity. Rarely do humanitarian organizations make decisions through rules and hierarchy (Balcik et al., 2010; Moshtari, 2016). Instead, humanitarian organizations engaged in disaster relief operations must process large amounts of data to make decisions that improve aid coordination in disaster relief operations. A growing stream of literature focuses on the application of big data in the humanitarian supply chain (Fawcett and Fawcett, 2013; Goswami et al., 2018; Papadopoulos et al., 2017; Dubey et al., 2018a). However, it remains unclear how BDA can be effective in building trust and enhancing collaboration between diverse actors, especially civil and military organizations engaged in urgent disaster relief operations. (We employ the term "swift trust" to denote the rapid formation of trusting relationships as will be discussed later.) In fact, both the conceptual and empirical contributions in humanitarian setting are still in a nascent stage, making it difficult to compare and accumulate results to draw meaningful conclusions. Hence, we aim to investigate how use of information gathered using BDAC under different organization settings can improve swift trust among civil and military actors engaged in disaster relief operations and can further improve collaboration among these actors. In this study, we focus on two important outcomes: swift trust and collaboration among humanitarian organizations involved in disaster relief operations. Specifically, we address the first research question:

RQ1. What are the effects of BDA on swift trust and collaboration among humanitarian organizations?

Boyd et al. (2012) argue that direct linkage models are crucial, but they often fail to provide sufficient insight to explain reality. An effective organizational cultural fit between supply chain partners fosters joint inventory management (Cadilhon et al., 2005), prevents quality and delivery issues (Pressey et al., 2007), and promotes a healthy relationship between organizations (Inemek and Matthyssens, 2013). A poor organizational cultural fit between buyers and suppliers often leads to lower collaboration performance and ineffective collaboration (Fawcett et al., 2015). Rodon et al. (2012) argue that in a humanitarian context, the cultural differences between organizations could hamper effective disaster relief responses. Organizational culture is a key factor in supply chain management practices and innovative information 
systems adoption (Khazanchi et al., 2007; Liu et al., 2010). Leidner and Kayworth (2006) argue that an organization is more likely to adopt an information system if the values embedded in the system fit its culture. Studies on the influence of organizational culture on technology-enabled collaboration between civil and military organizations in the humanitarian supply chain are limited. Thus, we address the second research question:

RQ2. What are the effects of organizational culture on the relationship between BDA and swift trust/ collaborative performance?

We answer the research questions using a sample of 373 international NGOs and military organizations involved in coordination with internal and external partners. We tested the theoretical model using cross-sectional data to validate the constructs and test the research hypotheses. In doing so, we add to the understanding of the links between BDA and swift trust/collaborative performance and the effect of organizational culture on the links between BDA and swift trust/collaborative performance, thus contributing to the growing humanitarian operations and BDA literature. From a managerial perspective, we provide theory-focused and empirically-tested evidence to help managers understand the application of BDA in building swift trust in the humanitarian supply chain and improving collaboration between civil and military organizations.

The rest of the paper is organized as follows. The second section deals with the theoretical framing. The third section focuses on theoretical framework and hypotheses development. In the fourth section, we describe the research design used to gather and validate data. The fifth section addresses data analysis, detailing the method of statistical analysis and presenting the results. The sixth section discusses the research contributions and the managerial implications of the study. Finally, we conclude the study.

\section{Theory development}

Galbraith (1974) argues that only rarely can organizations rely on "mechanistic models" of decision-making through rules, hierarchy, targets and goals. Instead, humanitarian organizations need to process large amounts of data to make decisions that can reduce the negative impacts of disaster on human lives and help to regain normality. Historically, humanitarian organizations have manually analyzed the information available from local government bodies. Now increasingly, humanitarian organizations are using information extracted using unstructured data in the form of satellite images, Twitter, YouTube, Facebook etc., in disaster relief operations (Yates and Paquette, 2011; Papadopoulos et al., 2017; Ragini et al., 2018). In this section, we present the theories underpinning the study.

\subsection{Organizational information processing theory (OIPT)}

Thompson (1967) first conceptualized the organizational information processing theory (OIPT) and Galbraith $(1974,1977)$ and Tushman and Nadler (1978) further developed the theory. The OIPT deals with organizational design, structures, and information processing capabilities. OIPT attempts to explain organizational behavior by examining the flow of information in and around organizations (Smith et al., 1991). OIPT argues that an organization needs to process information with different levels of uncertainty to extract insights that can help it achieve a competitive advantage. Hence, uncertainty drives the need for information processing; uncertainty is defined as "the difference between the amount of information required to execute a task and the level of information already available with the organization" (Galbraith, 1973, p.5). Galbraith (1973) further suggests seven strategies to cope with the various levels of uncertainty under which organizations function. When uncertainty is low, an organization may adopt any of three strategies to cope: (1) coordination by rule or programs; (2) employment of hierarchies; and (3) coordination by targets or goals.
However, in the case of high uncertainty, an organization may reduce the information processing need by creating (4) slack resources; and (5) self-constrained tasks. Next, an organization may increase its information processing capacity via (6) investment in vertical information systems; and (7) by creating lateral relations. Additionally, Galbraith (1974) further suggests eight strategies to reduce uncertainty via the control of an organization's environment through long-term associations or coalitions. We argue that by improving information visibility, decision-making becomes more effective. Srinivasan and Swink (2018) argue that a vertical information system enables an organization to process data efficiently and draw rich insights to make new plans rapidly with minimal costs. Further, the proper alignment of information processing needs and information processing capabilities enhances organizational performance (Premkumar et al., 2005; Srinivasan and Swink, 2015, 2018; Fan et al., 2017).

\subsection{Swift trust}

Golicic et al. (2003) argue that trust is a critical factor for effective coordination in a supply chain network. Management scholars note that a high level of trust among partners in a network leads to better coordination (Gulati and Singh, 1998; Fawcett et al., 2012) and supply chain performance in both the commercial context (see Fawcett et al., 2012) and the humanitarian context (see Dubey et al., 2017a; Lu et al., 2018). Rousseau et al. (1998) argue that trust is a concept that has been studied from a range of perspectives, including the economic, sociological, and psychological. Morgan and Hunt (1994, p.23) further define trust as "confidence in an exchange partner's reliability and integrity" and that "confidence on the part of a trusting party results from the firm belief that the trustworthy party is reliable and has high integrity, which is associated with such qualities as competent, honest, fair, responsible, helpful and benevolent".

However, in hastily formed networks in emergency logistics operations during sudden onset disasters, trust is limited (Tatham and Kovács, 2010; Hyllengren et al., 2011). Humanitarian operations require actors from a variety of organizations to work together, often without prior experience, for coordination and collaboration in the field (Hyllengren et al., 2011; Dubey et al., 2017a; Lu et al., 2018). While they share the goal of helping victims, they rarely have extensive professional joint training. This is especially true in developing countries, which tend to have misgivings about international humanitarian relief organizations for political or religious reasons (Tatham and Kovács, 2010; Lu et al., 2018). Hence, humanitarian relief organizations in such situations may design, migrate, and reorganize in an unstructured way. Trust building in such cases must occur in a short amount of time (Lu et al., 2018).

Meyerson et al. (1996) coined the term "swift trust" to describe what must occur when bringing temporary teams together with a clear purpose, a common task, and a finite life span. Tatham and Kovács (2010) argue that individuals are often glued together via "swift trust" following natural disasters. The definition offered by Meyerson et al. (1996) is founded in Goodman and Goodman (1976), who identify the social constraints and resources found in temporary systems. Hence, in such a situation, the trust must be built quickly to improve the success of the humanitarian aid supply network. Tatham and Kovács (2010) argue that "swift trust" is essential to building coordination among humanitarian supply chain actors.

\subsection{Organizational culture}

Deshpandé et al. (1993) define organizational culture as a collection of shared assumptions, values, and beliefs that is reflected in its practices and goals and further helps its members understand the organizational functions. This definition is further corroborated by other management scholars (see, Khazanchi et al., 2007; Lewis and Boyer, 2002; Leidner and Kayworth, 2006; Liu et al., 2010; Giorgi et al., 2015; 
Dubey et al., 2017b; Prasanna and Haavisto, 2018). Liu et al. (2010) further argue that organizational culture affects how the firm responds to external events and makes strategic choices. Prasanna and Haavisto (2018) classify organizational culture into five different models: values (what we prefer, hold dear, or desire) (Cameron and Quinn, 2011), stories (verbal or written narratives) (Vaara and Tienari, 2011), frames (filters or brackets that expand the horizon) (Smets et al., 2012), toolkits (sets of stories, frames, categories, rituals, and practices which actors draw upon to make meaning or take action) (McPherson and Sauder, 2013), and categories (social constructions or classifications which define and structure the conceptual differences between objects, people, and practices) (Wry et al., 2014). This study adopts the framework of flexibility-control orientation in the competing value model (CVM) proposed by Quinn and Rohrbaugh (1983). The CVM allows the comparison of value orientations within and between organizations (Lewis and Boyer, 2002; Liu et al., 2010). Hence, we argue that CVM is an appropriate model for organizational culture studies conducted in different organizations participating in disaster relief operations (Prasanna and Haavisto, 2018). In addition, the CVM offers a reliable quantitative way to study organizational culture (Liu et al., 2010). The validity of its measures was tested in prior studies (e.g. Deshpandé et al., 1993; Khazanchi et al., 2007; Liu et al., 2010). Hence, the CVM can be adopted in empirical studies to investigate the role of organizational culture in the adoption of innovative practices such as big data analytics (Ralston et al., 2006; Liu et al., 2010).

\subsection{Interorganizational collaboration}

Interorganizational collaboration in the context of the supply chain has gained increased attention from operations management scholars (Barratt, 2004; Balakrishnan and Geunes, 2004; Cao and Zhang, 2011; Durugbo, 2015). Supply chain collaboration can be classified into two groups (Cao and Zhang, 2011): relationship-based (Bowersox et al., 2003) and process-driven (Mentzer et al., 2001). Relationship-based collaboration is demonstrated by forming close, long-term partnerships in which parties actively share information and resources to achieve a common goal. On the other hand, process-driven collaboration occurs when two or more organizations engage to achieve common goals (Simatupang and Sridharan, 2002; Moshtari, 2016; Prasanna and Haavisto, 2018). Gulati et al. (2012) argue that interorganizational collaboration as a concept must include two dimensions: co-operation and co-ordination. Co-operation entails setting collaborative goals and deciding on the amount of resources (e.g. competent human resources, knowledge, or experiences) allocated to achieve those goals (Gulati et al., 2012; Moshtari, 2016). On the other hand, co-ordination refers to the efforts in aligning organizational tasks or actions to achieve cooperatively specified goals (Gulati et al., 2012; Moshtari, 2016).

\subsection{Big data analytics (BDA)}

Management scholars argue that BDA, as an organizational capability, may help organizations to gain a competitive edge (Hazen et al., 2014; Gupta and George, 2016; Akter et al., 2016; Fosso Wamba et al., 2015, 2017; Wang et al., 2016; Srinivasan and Swink, 2018; Dubey et al., 2018b). Agarwal and Dhar (2014) argue that BDA enables an organization to collect and analyze data to gain critical insights. Ravichandran and Lertwongsatien (2005) examine how information systems resources and capabilities are an important source of competitive advantage. Srinivasan and Swink (2018) argue that the main difference between BDA and conventional decision support technologies is the use of large volume, high velocity, and large varieties of data sources. In this study, we have adopted the definition of BDA according to Srinivasan and Swink (2018, p. 3): "an organizational facility with tools, techniques, and processes that enable a firm to process, organize, visualize, and analyze data, thereby producing insights that enable data-driven operational planning, decision making, and execution".
We argue, based on Galbraith's (2014) findings, that BDA capability enables firms to enhance their information processing capacity to extract critical insights from data gathered from multiple sources. LaValle et al. (2011) emphasize BDA capabilities as a bundle of tangible and intangible resources, such as IT tools and processes. Waller and Fawcett (2013) argue that how efficiently and effectively firms can use advanced quantitative techniques, such as statistical methods, optimization, and simulation, to draw useful insights in their decision-making process, plays a critical role. The insights obtained via BDA can be used for improving visibility in the humanitarian supply chain and coordination among humanitarian actors (Dubey et al., 2018a).

\subsection{Hypotheses}

An essential premise of OIPT is that a better information processing capability yields greater organizational performance (Galbraith, 1973, 1974; Altay and Pal, 2014; Srinivasan and Swink, 2018). In the age of the internet, ICTs (information and communication technologies) increasingly play an important role in building effective coordination in crisis response operations (Wentz, 2006; Akhtar et al., 2012; Kabra and Ramesh, 2015; Dubey et al., 2018a). Heaslip et al. (2012) argue that civil-military coordination is of critical importance to both the planning and implementation of assistance during the recovery process. Wentz (2006) notes some of the critical areas for civil-military coordination as: security; essential services, such as food, water, sanitation, medical assistance, and shelter; logistics; communications; transportation; and information. The need for ICT capability is universal across these areas; the effectiveness of the early phase of the disaster relief operations will play a significant role in the overall success of the mission (Wentz, 2006; Akhtar et al., 2012; Janssen et al., 2010). Balcik et al. (2010) argue that information sharing is vital because no single entity whether an NGO or a military organization - can be the source of all required data. The sharing of critical information not only reduces duplication of efforts but also enhances collaboration, creating a common pool of knowledge so that critical insights can be drawn using appropriate data analytics techniques (Dubey et al., 2018a). Tatham and Rietjens (2016) argue that cooperation and coordination networks must be designed to improve visibility and transparency among civilian and military organizations. Balcik et al. (2010) argue that diversity among humanitarian actors is advantageous because it allows complementary capabilities, resources, and expertise (Wentz, 2006; Boin et al., 2010; Heaslip et al., 2012; Tatham and Rietjens, 2016).

While in disaster response mode, the main goal of military organizations is to create a safe and secure environment so that civilian agencies can conduct humanitarian relief efforts and assume responsibilities for civil policing, justice, governance, and economic reconstruction (Wentz, 2006). In the absence of adequate security, military organizations find themselves obliged to provide both security and temporarily engage in disaster relief efforts and other aspects of the reconstruction phase until it is safe for civil organizations to take over those disaster relief tasks. These situations known as complex environments (Wentz, 2006) require information between the civil and military organizations to be carefully managed (Tatham and Rietjens, 2016). Achieving a shared civil-military vision, managing shared expectations, facilitating collaboration, and sharing information are crucial for disaster relief operations (Egnell, 2006; Heaslip, 2011; Heaslip et al., 2012; Altay and Labonte, 2014). Prasad et al. (2016) argue that humanitarian organizations with high visibility and effective information-sharing capabilities are better positioned to develop and deploy systems and processes for supporting analytics capabilities. Conversely, organizations that invest in developing analytics capabilities are most likely to invest in visibility because visibility provides data upon which analytics systems and processes operate. Absence of swift trust is a fundamental source of tension among the civilian and military organizations (Balcik et al., 2010; Tatham and Kovács, 2010; Heaslip et al., 2012). Tatham and Rietjens (2016) argue that for effective cooperation 
and coordination, it is important to understand the roles, relationships, capabilities, motivations, and information-sharing needs in complex environments. Thus, we can argue that big data analytics capability and swift trust are complementary, in the sense that each demands and supports the other. Both analytics capability and swift trust emerge from visibility and information sharing. Hence, we expect humanitarian organizations to understand the connections between analytics capability, swift trust, and collaborative performance. Following this line of reasoning, we posit the hypotheses:

H1. Big data analytics capability is positively associated with swift trust.

H2. Big data analytics capability is positively associated with collaborative performance.

H3. Swift trust is positively associated with collaborative performance.

Most organizations have distinct organizational cultures, which dictates their rules, regulations, viewpoints, perspectives, and operating procedures (Dowty and Wallace, 2010; Prasanna and Haavisto, 2018). An organization's culture stems from its unique history, mission, structure, and leadership (Wentz, 2006). Previous studies advocate organizational culture as the guide for organizational strategies (Lewis and Boyer, 2002; Khazanchi et al., 2007; Liu et al., 2010). Liu et al. (2010) argue that organizational culture can influence a manager's ability to process information, rationalize, and exercise discretion in their decision-making processes. Prasanna and Haavisto (2018) argue that flexibility-oriented (i.e. developmental and group culture) and control-oriented cultures (i.e. rational and hierarchical culture) have different effects on the firm's interpretations of external events, and thus affect their responses to the expectations and requirements of the environment in various ways (Deshpandé et al., 1993; Khazanchi et al., 2007). For instance, when compared to military organizations, civil relief organizations are less formal, less authoritarian, and less focused on internal traditions or security concerns; military organizations are highly hierarchical and authoritarian, respectful of internal traditions, and trained to be highly secretive for operational security. NGOs, for example have a much "flatter" structure (Heaslip, 2011; Tatham and Rietjens, 2016), which means most NGOs enjoy greater flexibility and autonomy than their military counterparts (Wentz, 2006). Leidner and Kayworth (2006) argue that organizational culture plays a significant role on IT adoption and diffusion. Hoffman and Klepper (2000) note that organizations low in sociability and high in solidarity experience more favorable outcomes with technology assimilation than those with more networked (high sociability and low in solidarity) cultures. Similarly, Kitchell (1995) found that organizations with open or flexible cultures and a long-term orientation evidence a greater propensity to adopt advanced manufacturing technology. Ruppel and Harrington (2001) conclude that intranet adoption is much more likely to succeed in development (values emphasizing flexibility and innovation) type cultures. Based on this line of reasoning, we hypothesize:

$\mathrm{H} 4 \mathrm{a} / 4 \mathrm{~b}$. Organizational flexible orientation positively moderates the relationship between big data analytics and swift trust/collaborative performance.

$\mathrm{H} 5 \mathrm{a} / 5 \mathrm{~b}$. Organizational control orientation negatively moderates the relationship between big data analytics and swift trust/collaborative performance.

In addition, two control variables that may influence swift trust and collaborative performance were included in the statistical analysis. Temporal orientation (TO) is used by Moshtari (2016) to denote the length of time participating partners in disaster relief operations expect to work together and their orientation to the long term. Moshtari (2016) argues that engagement in long-term collaborative initiatives is often considered time consuming and requires resource investment (e.g. human resources and information) over the long term. Next, we control for interdependency perception. Interdependency positively affects the mutual trust and commitment because interdependence increases the partners' desire to maintain the relationship (Moshtari, 2016).

\section{Research design}

The empirical context of this study includes numerous and diverse participants involved in humanitarian operations in countries across Asia, Europe, Africa, North America, and South America (see Appendix C). The collaboration among civil and military organizations focuses on partnership. Therefore, the constructs identified in the study were conceptualized to study the collaboration between civil and military organizations from both NGOs' and military forces' perspectives. The measures were based on the perceptions of multiple respondents (Ketokivi and Schroeder, 2004) who were expected to have knowledge and experience about partnerships during disaster relief operations. The target respondents are project directors, deputy directors, and managers from military forces of different countries, developed-country government aid agencies, UN specialized agencies, international and local NGOs, as well as service providers and contractors because they are the persons responsible for the setting up and managing collaborative relationships. We contacted the United Nations Office for the Coordination of Humanitarian Affairs (OCHA) to get contact information of the international NGOs and military forces. The OCHA offers diverse services, so this sample minimizes any specific category effect (Palmatier et al., 2007; Moshtari, 2016).

\subsection{Survey instrument}

To test the proposed theoretical model and research hypotheses, we followed two phases of construct definition and identification of measurement items (Chen and Paulraj, 2004; Eckstein et al., 2015; Lucianetti et al., 2018) (see Appendix A). First, we reviewed operations management and organizational studies literature. This literature provided us the construct's definitions and the first list of measurement items for each construct, which we compared with previous studies. Next, we adapted them to fit the context of humanitarian operations management (see Moshtari, 2016; Dubey et al., 2018a). They are measured on a five-point Likert scale with anchors ranging from strongly disagree (1) to strongly agree (5) in order to ensure high statistical variability among the survey responses (see, Kim et al., 2009; Dwivedi et al., 2013) (see Appendix B).

Prior to data collection, the instrument was pre-tested for content validity in two phases (Chen and Paulraj, 2004). In the first phase, we invited six experienced researchers to provide their critical input on the questionnaire, specifically analysing them for ambiguity, clarity, and appropriateness of the items used (DeVellis, 1991). We further asked these researchers to assess the extent to which the indicators sufficiently addressed the subject area (Dillman, 2007). Based on these researchers' input, we further modified the instrument to improve the clarity and appropriateness of the measures for the constructs (Chen and Paulraj, 2004). In the second stage, we e-mailed the questionnaire to five managers from the United Nations Office for the Coordination of Humanitarian Affairs civil-military coordination section (OCHA United Nations, 2016). These managers were asked to review the questionnaire for structure, readability, ambiguity, and completeness. The final survey instrument incorporated the feedback received from these executives, which enhanced the clarity of the instruments. Thanks to these checks, the survey instrument developed was judged to exhibit high content validity.

\subsection{Data collection}

We used data collected in 2014-17 from civil and military organizations as an extended part of the big data and predictive analytics in humanitarian supply chains project (Dubey et al., 2018a). We emailed 
an invitation letter to 4678 potential respondents from 1560 organizations and followed-up with three e-mail reminders. In all communications, we assured potential respondents that their information would remain anonymous and confidential. The survey responses were carefully examined and in some cases, eliminated if they failed to meet certain criteria. We followed the key informant approach, screened the responses, and eliminated those who had not worked on projects involving civil and military organizations.

Ultimately, we used responses from 373 organizations (see Appendix C), an effective rate of $23.91 \%$, with three participants from each organization (a total of 1119 multiple responses). The response rate is quite acceptable in comparison to similar studies conducted in past on collaborative relationships (e.g., 13\% response rate in Moshtari (2016) or $6 \%$ response rate in Cao and Zhang (2011)). This high response rate was achieved by contacting each participant personally by telephone and assuring them they would be able to review the findings. We further performed a non-response bias test using ANOVA analysis for each of the examined constructs (Armstrong and Overton, 1977; Moshtari, 2016). The test yields no significant difference between earlywave and late-wave groups of respondents. Hence, we conclude that non-response bias was not a potential concern in this study.

All participants are key informants who hold senior positions (head or director of mission) from military organizations and senior managers from civil organizations. $36.46 \%$ respondents are from military organizations, $30.03 \%$ respondents are from developed-country aid agencies, $15.01 \%$ are from international NGOs, $12.33 \%$ respondents are volunteers from university or faith-based teams, and $6.17 \%$ are service providers and contractors (see Appendix C).

\section{Analysis and results}

At the time of this work, the relationship between big data analytics capability and swift-trust/collaborative performance had not been examined in the literature; therefore there was no theoretical foundation anticipating their relationships. Hence, PLS was an appropriate technique for data analysis (Peng and Lai, 2012). Kock (2017) argues that criticism of traditional PLS-SEM methods are due to them being composite-based, not factor-based. That is, in traditional PLS-SEM methods, latent variables are estimated as weighted aggregations of indicators without the inclusion of measurement errors (Henseler et al., 2014; Kock, 2017). The measurement errors usually serve as extra indicators that often complement the actual indicators; together, the actual indicators and measurement errors constitute factors. Kock (2017) argues that without considering measurement errors, the use of composites instead of factors leads to some known sources of bias; path coefficients tend to weaken with respect to their corresponding true values. Recent methodological developments building upon traditional PLS techniques have helped to bridge the gap between factor-based and compositebased structural equation modelling (SEM) techniques (Kock, 2015a; Sarstedt et al., 2016). We therefore used WarpPLS 6.0, which is a popular PLS technique that has been recently used in SEM (Kock, 2017).

\subsection{Multiple rater agreement measures}

Using three participant from each respondent organization, we needed to assess the validity of the participants' views. Table 1 provides the results of inter-rater agreement analysis using four different methods discussed in literature: the percentage method (Shortell and Zajac, 1990; Boyer and Verma, 2000; Ketokivi and Schroeder, 2004), the ratio method (James et al., 1984; Boyer and Verma, 2000; Ketokivi and Schroeder, 2004), the inter-class correlation coefficient (Shrout and Fleiss, 1979; Boyer and Verma, 2000), and paired t-test (Boyer and Verma, 2000; Ketokivi and Schroeder, 2004).

Hence, we conclude based on the findings of Table 1 that the interrater agreement in the data was acceptable.

\subsection{Measurement model reliability and validity}

We follow two stages for estimating the model as suggested in literature (see, Peng and Lai, 2012; Moshtari, 2016). First, we examine the reliability and validity of the measurement model. Second, we analyze the structural model with reflective constructs. Table 2 shows the result of confirmatory factor analysis (i.e. the range of factor loadings, the scale composite reliability, and average variance extracted), which establishes the convergent validity of the constructs of the theoretical model (see Fig. 1). All the items loadings are greater than 0.5 and significant at the 0.01 level, indicating convergent validity at indicator level (Bagozzi et al., 1998). All scale composite reliabilities are greater than 0.7 , indicating acceptable reliability (Fornell and Larcker, 1981). All AVE values are greater than 0.5, except FO, whose value is 0.47 . In comparison to Liu et al. (2010) all the items loadings are less than 0.8 . This may be due to response bias (see, Netemeyer et al., 1990; Rana and Dwivedi, 2015). Hence, in future studies in humanitarian settings we call for further scale refinement. Overall, the results confirm the convergent validity of the constructs is acceptable.

We examine the discriminant validity of measures. For this, we observe the rotated factor loadings matrix, which demonstrates that no item loads higher on another construct than it does on its associated construct (i.e. we obtained parsimonious structure). Thus, we conclude that all reflective measures demonstrate acceptable discriminant validity. Finally, we examine the constructs' discriminant validity, which represents the extent to which measures of a given construct differ from measures of other constructs in the theoretical model (see Fig. 1). Following the arguments of Fornell and Larcker (1981), we examine whether the square root of each construct's AVE in a leading diagonal of a construct correlations matrix is greater than the correlation coefficient of the focal construct and other constructs. Table 3 confirms the discriminant validity of the constructs is acceptable.

\subsection{Common method bias (CMB)}

Because we used a survey-based instrument to gather data, there is potential for CMB (Podsakoff and Organ, 1986; Podsakoff et al., 2003). To protect the integrity of the results, we use multi-informant data following the suggestions of Ketokivi and Schroeder (2004) to minimize CMB. In addition, we test for CMB in multiple ways. First, we perform Harman's one factor test. Second, we test for CMB using the correlation marker technique (Lindell and Whitney, 2001). We use an unrelated variable to partial out correlations caused by CMB. Additionally, we calculate the significance value of the correlations using equations formulated by Lindell and Whitney (2001). We observe minimal differences between the adjusted and unadjusted correlations. Furthermore, the significance of the correlations did not change. Based on these results, we conclude that $\mathrm{CMB}$ might not have a significant effect on this study.

Causality is an important aspect that must be addressed before proceeding to the hypotheses test (Guide and Ketokivi, 2015). We conceptualize BDAC as an exogenous model variable to the swift trust and collaborative performance but not the other way around. Because the stated relationships between BDAC and swift trust/collaborative performance are not examined in extant literature, the causality test was important in this study. Following Kock's (2015b) recommendations, we calculate nonlinear bivariate causality direction ratio (NLBCDR). The NLBCDR is a measure of the extent to which bivariate nonlinear coefficients of association provide support for the hypothesized directions of the causal links in the proposed theoretical model (Kock, 2015b). The acceptable value should be $\geq 0.7$. In this case, we note that NLBCDR $=0.96$ (approx.), which is greater than the critical value. We therefore conclude that endogeneity is not a major concern. We further examine the model fit and quality indices in Appendix D. 
Table 1

Measures of inter-rater agreement.

\begin{tabular}{|c|c|c|c|c|}
\hline Constructs & Percentage method $(\%)$ & Ratio method & Inter-class correlation coefficient & Paired $t$-test \\
\hline Big Data Analytics Capability (BDAC) & 92 & 0.81 & 0.42 & Not-significant \\
\hline Swift-Trust (ST) & 91 & 0.79 & 0.36 & Not-significant \\
\hline Collaborative Performance (CP) & 88 & 0.77 & 0.42 & Not-significant \\
\hline Flexible Orientation (FO) & 86 & 0.76 & 0.43 & Significant \\
\hline Control Orientation (CO) & 84 & 0.75 & 0.23 & Not-significant \\
\hline Temporal Orientation (TO) & 85 & 0.79 & 0.34 & Not-significant \\
\hline Interdependency (I) & 87 & 0.76 & 0.28 & Significant \\
\hline
\end{tabular}

Table 2

Measurement properties of constructs (convergent validity) $(\mathrm{N}=373$ ).

\begin{tabular}{llllll}
\hline ITEMS & FACTOR LOADINGS & VARIANCE & ERROR & SCR & AVE \\
\hline BDAC1 & 0.80 & 0.64 & 0.36 & 0.83 & 0.55 \\
BDAC2 & 0.81 & 0.66 & 0.34 & & \\
BDAC3 & 0.78 & 0.61 & 0.39 & & \\
BDAC4 & 0.54 & 0.29 & 0.71 & & \\
ST1 & 0.77 & 0.60 & 0.40 & 0.82 & 0.60 \\
ST2 & 0.74 & 0.55 & 0.45 & & \\
ST3 & 0.81 & 0.65 & 0.35 & & \\
CP2 & 0.77 & 0.60 & 0.40 & 0.75 & 0.51 \\
CP3 & 0.76 & 0.58 & 0.42 & & \\
CP4 & 0.59 & 0.35 & 0.65 & & \\
FO1 & 0.66 & 0.44 & 0.56 & 0.78 & 0.47 \\
FO2 & 0.68 & 0.47 & 0.53 & & \\
FO3 & 0.74 & 0.54 & 0.46 & & \\
FO4 & 0.66 & 0.44 & 0.56 & & \\
CO1 & 0.76 & 0.58 & 0.42 & 0.79 & 0.55 \\
CO2 & 0.73 & 0.53 & 0.47 & & \\
CO3 & 0.74 & 0.55 & 0.45 & & \\
TO1 & 0.83 & 0.68 & 0.32 & 0.80 & 0.57 \\
TO2 & 0.56 & 0.31 & 0.69 & & \\
TO3 & 0.85 & 0.73 & 0.27 & \multirow{2}{*}{0.79} & 0.65 \\
I1 & 0.81 & 0.65 & 0.35 & 0.79 & \\
I2 & 0.81 & 0.65 & 0.35 & & \\
\hline
\end{tabular}

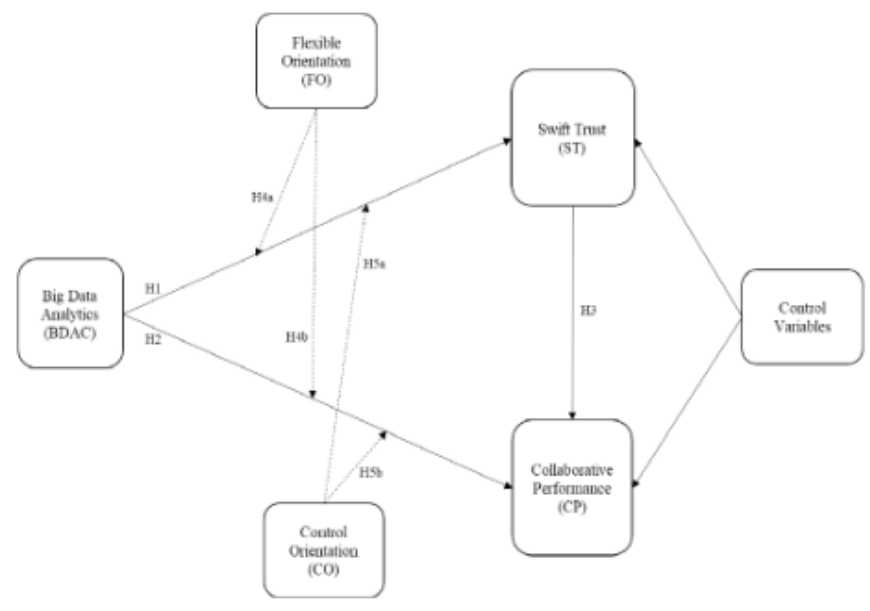

Fig. 1. Conceptual framework.

\subsection{Model estimation and analysis}

Because PLS does not follow multivariate normal distribution, traditional parametric-based techniques for significance tests are not appropriate for this study. PLS uses a bootstrapping procedure to estimate standard errors (SEs) and significance of the parameter estimates (Chin, 1998; Peng and Lai, 2012; Akter et al., 2017). We report the PLS path coefficients and p-values in Table 4 (H1, H2, H3, H4a/4b, H5a/5b).

The links BDAC $\rightarrow$ ST $(\beta=0.28, p<0.01), \mathrm{BDAC} \rightarrow \mathrm{CP}(\beta=0.36$, $\mathrm{p}<0.01)$ and $\mathrm{ST} \rightarrow \mathrm{CP}(\beta=0.23, \mathrm{p}<0.01)$ are positively related. Hence, we can argue based on the direction of $\beta$ and its corresponding $p$
Table 3

Construct correlations (discriminant validity) $(\mathrm{N}=373)$.

\begin{tabular}{lccccccc}
\hline & BDAC & ST & CP & FO & CO & TO & I \\
\hline BDAC & $\mathbf{0 . 7 4}$ & & & & & & \\
ST & 0.00 & $\mathbf{0 . 7 7}$ & & & & & \\
CP & 0.14 & 0.43 & $\mathbf{0 . 7 1}$ & & & & \\
FO & 0.17 & 0.31 & 0.58 & $\mathbf{0 . 6 9}$ & & & \\
CO & 0.24 & 0.32 & 0.41 & 0.39 & $\mathbf{0 . 7 4}$ & & \\
TO & 0.15 & 0.35 & 0.69 & 0.37 & 0.60 & 0.75 & \\
I & 0.16 & 0.33 & 0.60 & 0.43 & 0.64 & 0.39 & $\mathbf{0 . 8 1}$
\end{tabular}

Notes: BDAC, big data analytics capability; ST, Swift Trust; CP, Collaborative Performance; FO, Flexibility Orientation; CO, Controlled Orientation; TO, Temporal Orientation; I, Interdependency. The square root of AVE is shown in bold on the diagonal.

Table 4

Structural estimates $(\mathrm{N}=373)$.

\begin{tabular}{|c|c|c|c|c|c|}
\hline Hypothesis & Effect of & Effect on & $\beta$ & p-value & Results \\
\hline $\mathrm{H} 1$ & BDAC & ST & 0.28 & $\star \star \star \star$ & Supported \\
\hline $\mathrm{H} 2$ & BDAC & $\mathrm{CP}$ & 0.36 & $\star \star \star *$ & Supported \\
\hline H3 & ST & $\mathrm{CP}$ & 0.23 & $\star \star \star \star$ & Supported \\
\hline $\mathrm{H} 4 \mathrm{a}$ & $\mathrm{BDAC}{ }^{\star} \mathrm{FO}$ & ST & 0.05 & * & Not supported \\
\hline $\mathrm{H} 4 \mathrm{~b}$ & $\mathrm{BDAC} * \mathrm{FO}$ & $\mathrm{CP}$ & 0.48 & $\star * *$ & Supported \\
\hline $\mathrm{H} 5 \mathrm{a}$ & $\mathrm{BDAC}^{\star} \mathrm{CO}$ & ST & 0.06 & * & Not supported \\
\hline \multirow[t]{6}{*}{$\mathrm{H} 5 \mathrm{~b}$} & $\mathrm{BDAC}^{*} \mathrm{CO}$ & $\mathrm{CP}$ & -0.46 & $* * *$ & Supported \\
\hline & \multicolumn{4}{|c|}{ Control variables } & \\
\hline & I & ST & 0.98 & $\star * *$ & \\
\hline & I & $\mathrm{CP}$ & 0.82 & $\star \star \star *$ & \\
\hline & TO & ST & 1.29 & $\star \star \star *$ & \\
\hline & To & $\mathrm{CP}$ & 0.22 & $\star * *$ & \\
\hline
\end{tabular}

Notes: BDAC, big data analytics capability; ST, Swift Trust; CP, Collaborative Performance; FO, Flexibility Orientation; CO, Controlled Orientation; TO, Temporal Orientation; I, Interdependency. ${ }^{*} \mathrm{p}>0.1 ;{ }^{* *} \mathrm{p}<0.01$.

values that hypotheses $(\mathrm{H} 1-\mathrm{H} 3)$ are supported. The control variables TO and I have positive and significant effects on ST and CP. We interpret the observations as evidence that $\mathrm{TO}$ and I have significant roles to play in the connectivity of BDAC and ST/CP.

Next, hypotheses $\mathrm{H} 4 \mathrm{a} / 4 \mathrm{~b}$ and $\mathrm{H} 5 \mathrm{a} / 5 \mathrm{~b}$ are tested for the moderation effect of FO/CO on the path connecting BDAC and ST/CP. We find that H4a $(\beta=0.05, p>0.1)$ is not supported. We interpret this observation because the FO has no significant effect on the path connecting BDAC and ST. H4b $(\beta=0.48, p<0.01)$ is supported, which suggests that FO has a significant effect on the path connecting BDAC and CP. Next, we find that H5a $(\beta=0.06, p<0.01)$ is not supported. With this, we can interpret that $\mathrm{CO}$ has no significant effect on the path connecting BDAC and ST. H5b $(\beta=-0.46, \mathrm{p}>0.01)$ is supported, which indicates that $\mathrm{CO}$ has a significant and negative effect on the path connecting BDAC and $\mathrm{CP}$.

We further examine the explanatory power of the proposed theoretical model. For this, we analyze the explanatory power $\left(\mathrm{R}^{2}\right)$ of the endogenous constructs as shown in Table 5. The $\mathrm{R}^{2}$ of ST is 0.80 (approx.) and CP is 0.88 (approx.), which is strong (Chin, 1998) (see Fig. 2). We calculate the effect size $\left(\mathrm{f}^{2}\right)$ value of BDAC using Cohen's $\mathrm{f}^{2}$ 
Table 5

$\mathrm{R}^{2}$, prediction and effect size $(\mathrm{N}=373)$.

\begin{tabular}{lllll}
\hline CONSTRUCT & $\mathrm{R}^{2}$ & $\mathrm{Q}^{2}$ & \multicolumn{2}{l}{$\mathrm{F}^{2}$ IN RELATION TO } \\
\cline { 3 - 5 } & & & $\mathrm{ST}$ & $\mathrm{CP}$ \\
\hline BDAC & - & - & 0.016 & 0.013 \\
ST & 0.80 & 0.231 & & \\
CP & 0.88 & 0.575 & & \\
FO & - & - & & 0.152 \\
CO & - & - & 0.464 & 0.575 \\
TO & & & 0.324 & \\
I & & & & \\
\hline
\end{tabular}

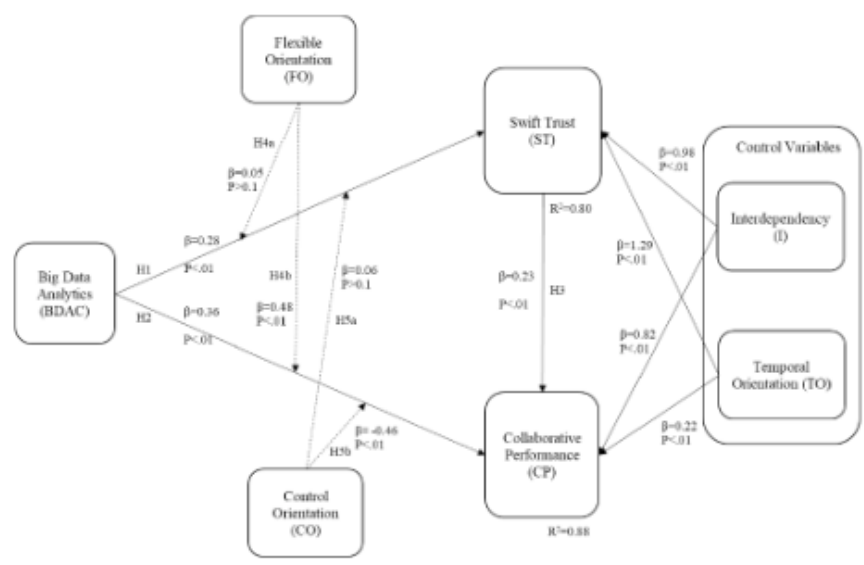

Fig. 2. Conceptual framework after SEM.

formula. Consequently, the effect size of BDAC on ST is (0.016) and on $\mathrm{CP}$ is $(0.013)$ which are greater than the cut-off value of zero. We further investigate the predictability of the model. Stone-Geiser's $Q^{2}$ values of endogenous constructs are ST $(0.231)$ and CP (0.575) (see Table 5) for BDAC, which are greater than zero. With these results, we find that the BDAC has significant predictive capability (Peng and Lai, 2012). Fig. 2 shows the conceptual framework after SEM analysis.

\subsection{Post hoc analysis using multi-level confirmatory factor analysis (MCFA)}

Social and behavioral research often concerns research problems that investigate the relationships between individuals and the larger context in which they live or operate (Hox, 2013; Bottoni, 2018). Hox (2013) argues that longitudinal data are becoming more common, where individuals are followed over a period to observe and model their development. Hence, in response to growing complexity, multilevel models and software (e.g. Mplus 8.1) have been introduced to combine in a statistically sound way variables defined at the individual and the group level. Initially, multi-level modelling was introduced, mostly in the context of individuals within groups; then the technique was rapidly extended to include longitudinal and repeated measures data (Goldstein, 1987). The multi-level analysis of repeated measures data, within individuals, does not assume that all individuals have the same number of measures. Multilevel structural equation modelling is more flexible than (multilevel) regression models. In the humanitarian setting, we have obtained repeated measures data (2014-2018) from humanitarian actors involved in disaster relief operations. On the organization level we have the outcome variable collaborative performance. We have two explanatory variables on the organization level, $B D A C$ and swift trust, and two class-level explanatory variables, control and flexible orientation. We conducted analyses using Mplus 8.1. The variables included in the model were continuous. Hence, analyses were performed on covariance matrix using robust weighted least squares estimator (WLSE) (Muthén, 1984). The goodness of fit (GoF) of the models was assessed via chi-square test, comparative fit index (CFI), and root mean square error of approximation (RMSEA) (Bentler, 1992; Hox et al., 2017). We also used standardized root mean square residual (SRMR). However, in multi-level modelling the SRMR is different from classical SEM, is computed separately within part (SRMR-W) and between part (SRMR-B) of the model. We have presented the descriptive statistics of the multi-level data (see Appendix E) and multi-level confirmatory factor analysis (MCFA) (see Appendix F). The MCFA breaks down the total sample covariance matrices using two matrices to analyze the factor structure at each level (Muthén, 1994; Preacher et al., 2010). The two level CFA model can be expressed as follows:

$C P i j=\beta 0 j+\beta 1 j(B D A C i j)+\beta 2 j(S T i j)+e i j$.

In this equation (1), $\beta 0 \mathrm{j}$ represents the intercept, $\beta 1 \mathrm{j}$ represents the slope for the continuous variable BDAC, $\beta 2 \mathrm{j}$ represents the slope for the continuous variable ST and eij is the usual residual error term. The subscript $\mathrm{j}$ is for the classes $(\mathrm{j}=1,2,3, . ., \mathrm{n})$ and the subscript $\mathrm{i}$ is for individual organization $(\mathrm{i}=1,2,3,4,5, \ldots, \mathrm{m})$. The eij are assumed to be normally distributed with a mean of zero and some variance that is estimated. We have denoted $\mathrm{ve}^{2}$ to denote the variance of the lowest level residual errors. Since the regression coefficients of the individuallevel variables vary across organizations; in the next step, we have explained the variation using explanatory variables at the second or higher level:

$\beta 0 j=\beta 00+\beta 01 *$ Organizational culture $(C O / F O) j+u 0 j$,

and

$$
\begin{aligned}
& \beta 1 j=\beta 10+\beta 11 * \text { Organizational culture }(C O / F O) j+u 1 j, \\
& \beta 2 j=\beta 20+\beta 21 * \text { Organizational culture }(C O / F O) j+u 2 j,
\end{aligned}
$$

Equation (2) predicts the average collaborative performance (CPij) among humanitarian actors $(\beta 0 \mathrm{j})$ in different organization settings (CO/FO). Equations (3) and (4) state the relationship between the CPij, BDACij and STij under moderating effect of CO/FO. The u terms $\mathrm{u} 0 \mathrm{j}$, $\mathrm{u} 1 \mathrm{i}$ and $\mathrm{u} 2 \mathrm{j}$ are residual error terms at organizational level. Before performing MCFA, we determined the variability between and within each indicator. The intra class coefficient (ICC) provides both a measure of the between organizations variability and the degree of the non-independence of the observations nested into organizations. The ICC represents the indicator's means variation between organizations divided by the total variation and can range from 0 (no between variation) to 1 (no within variation). There is no agree cut-off value for ICC, but most researchers agree that it should be greater than 0.05 (Hox et al., 2017). The ICC average value 0.281 ( $28 \%$ of the variability is due to between variance) indicates that there is enough between organizations variance to justify a multilevel approach. The fit indices (CFI, SRMR-W and SRMR-B) (see Appendix F), did not change going from model 2 to model 3 , so the measurement invariance seems confirmed. In other words, the relationships between the latent factors and the indicators are the same in all organizations. Thus the post hoc analysis has shown the validity of the findings across the civil and military organizations drawn from 373 organizations from 29 countries (see Appendix C).

\section{Discussion of results and implications to theory and practice}

The empirical findings paint an interesting picture of the relationship and complementarities among BDA, ST, FO, CO, and CP in a humanitarian aid setting. Table 4 provide a brief summary of the evidence based on the data, in support or non-support of the research hypotheses and the predictive capability of BDAC. Collectively, these findings have strong implications for current theory by raising new questions for research and providing significant directions to managers engaged in humanitarian relief operations.

Swift trust allows participating members to justify their decision to contribute (Robert et al., 2009) and further allows individuals to freely 
interact via information and knowledge sharing, which is often considered critical to the success of collaboration. Trust is even more important in the case of virtual teams engaged in disaster relief operations where members communicate via ICTs and are often geographically dispersed. These results demonstrate that BDA significantly influence ST and CP. Thereby, this study is the first to offer a rigorous empirical test of the effect of BDA on building swift-trust among humanitarian actors. It further helps to enhance collaboration among humanitarian actors engaged in disaster relief operations, which, as confirmed in previous research, is key to successful humanitarian relief operations (Prasad et al., 2016), The traditional view of trust would predict low levels of initial trust in virtual teams because team members have little past history and may not share common cultures (Robert et al., 2009; Tatham and Kovács, 2010; Lu et al., 2018). Robert et al. (2009) argue that the communication in an environment has a significant effect on the level of risk perceived. Individuals considered communication in an ICT-mediated environment to be inherently more risky than face-to-face communication. Barratt and Oke (2007) argue that competitive advantages stem from the ways in which technologies are used, rather than the actual technologies themselves. Srinivasan and Swink (2018) argue that interorganizational factors may be important in establishing effective forms of visibility, over and above the mere possession of information technologies that mostly provide data storage and transactional capabilities. Thus, based on these results, we argue that BDAC can help to enhance the information processing capability while the insights gathered via increased information processing capacity may help to reduce uncertainty, especially when organizations are operating in highly volatile environments and tasks are highly complex (i.e. highly interdependent). Thus, BDAC can improve the ST formation among the partners (i.e. civil and military organizations) engaged in disaster relief operations. Hence, we offer a fresh perspective to the ongoing debate surrounding the formation of swift trust in virtual and temporary teams.

In addition, the results show that flexible and control orientations have differential moderating effects on the relationship between BDAC and ST/CP. The findings reveal that FO and $\mathrm{CO}$ have no significant effect on the path joining BDAC and ST. This is contrary to our belief that FO may have a positive moderation effect on the path joining BDAC and ST or CO and may have a negative moderation effect on the path joining BDAC and ST. Hence, FO/CO may not help to enhance the effect of BDAC on ST formation. However, FO (+)/CO(-), has a significant moderation effect on the path joining BDAC and CP. We can interpret that civilian organizations commonly seek to achieve efficiency in the use of limited resources. Hence, they tend to expand their resources as far as possible and be less geared toward end states or goals. Hence, accountability may be less rigorous in comparison to their military counterparts. Civilian organizations often find themselves forced to be expedient and flexible during emergencies, yet they may lack the resources to adequately prepare themselves for long-term engagement. Hence, civilian organizations' flexibility and military organizations' precision may lead to conflict during relief operations. Information sharing is often considered less restrictive among civilian organizations than between civilian and military groups. On other hand, military personnel are often highly restrictive with their information and make operational security their highest priority. Thus, the insights gathered via BDAC may not be sufficient to improve the ST, as the civilian organizations are often reluctant to share their information with military groups. Yet, the insights gathered via BDAC may help to bridge the gap that results from information asymmetry between civil and military groups.

\subsection{Implications for theory}

Our study provides further evidence that BDAC can help to improve ST in temporary and virtual teams irrespective of their flexible or control orientation. It contributes to a better understanding of the organization's decision to adopt interorganizational innovations in an uncertain environment. Indeed, the application of OIPT in humanitarian operations is rather limited, whereas the literature in the supply chain, strategy, and information management has been using OIPT for quite some time following the seminal works by Galbraith (1973, 1974). These findings lend support to Galbraith's (1973) argument related to the interaction of organizational culture and structure, which together influence the ST and CP within a humanitarian setting. Previous studies provide insight into how BDAC adoption may affect the coordination or collaboration among the humanitarian organizations (Prasad et al., 2016; Dubey et al., 2018a), but the previous studies rarely provide insight into how organizational culture may affect BDAC adoption to enhance ST and CP among civil and military groups engaged in disaster relief operations. With the help of OIPT, we explain the relationship between BDAC, ST, CP, FO and CO. The results support the arguments of Galbraith (1973) and Srinivasan and Swink (2018) that if the information-processing requirement of an organization is dominated by its specific culture fit (i.e. flexible or control oriented), its information-processing capacity and the swift trust and collaborative performance increase. While the study provides some preliminary understanding, it further opens a new avenue for study exploring how institutional logic, in combination with organizational culture, can be used to explain under what context BDAC can improve ST.

\subsection{Implications for practice}

Our tests establish further empirical evidence (i.e. beyond anecdotal evidence) that initiatives to build trust or improve collaboration among civil and military organizations do indeed benefit from big data analytics capability. Therefore, we provide insights for managers into the distinct value of swift trust and collaboration as the challenges span differences in culture, language, organization, training and education, doctrine, planning, and analysis. Although informal personal relationships often play an important role in minimizing the organizational barriers to achieve information sharing (Robert et al., 2009) the informal process makes it difficult to address a wider audience or to institutionalize any standard procedures (Wentz, 2006). As a result, the BDAC in the age of large and complex data and face-to-face meetings often becomes the effective means to collaborate and share information in complex environments and post-disaster situations. Effectively gathering, compiling, analyzing and disseminating timely and relevant information is one of the major challenges for building trust and improving collaboration between civil and military organizations. Hence, a better information processing capability can improve the effectiveness of the humanitarian assistance. Thus, we conclude that the faster civilmilitary response organizations can identify, gather, analyze, and disseminate critical information, the more effective the response should become.

\subsection{Limitations and further research directions}

As with any other study, we caution our readers to evaluate our results and contributions in the light of limitations. We believe the limitations can be addressed by future study. We recognize that our AVE for factor FO is slightly below the normal threshold of 0.5 ; while this appears minor it is a cause for concern and for further work. Following Ketokivi and Schroeder's (2004) arguments, we gathered cross-sectional data using a survey-based instrument from multiple respondents within the same organization to avoid common method bias. However, we firmly believe that a longitudinal design would further minimize CMB (Podsakoff and Organ, 1986; Guide and Ketokivi, 2015) that otherwise undermines the validity of studies. Secondly, little research is available that focuses on what data and information are available in such contexts. Multiple organizations often generate the same information or use old data to derive insights, which may further negate the trust between civil-military organizations. OIPT offers 
guidance in the development of BDAC under which organizations can translate information-processing capabilities into better operational performance. Although we agree that the technical features of BDAC will continue to advance with the passage of time, we see no reason to believe that external situations regarding the role of flexible and control orientations will alter the effects of BDAC on ST/CP. No matter how comprehensive, precise, or automated analytics tools become, we can argue that the competitive advantage of the OIPT will depend on an organization's ability to gather accurate data and deliver timely and accurate information to other participating organizations to build rapid trust. However, it is not clear how institutional logic can shape organizational culture and further affect the adoption of BDAC to build swift trust among temporary and virtual teams. Hence, future studies can explore under what conditions BDAC can enhance swift trust and collaborative performance.

\section{Conclusions}

Achieving effective coordination, cooperation, and collaboration between civil and military organizations in disaster relief operations is one of the most complex and immensely difficult tasks. In reality, the practitioners need to understand that disaster relief operations include countless logistical challenges involving interoperability issues and redundancies. To mitigate such problems, organizations must understand the complexities involved and plan accordingly. The first step in collaboration is identifying points of agreement and disagreement that can be resolved. Civilian and military organizations often differ greatly in terms of their working styles and organizational cultures, but common ground can be found. Second, resource management is also critical to successful operations. A lack of trust is one of the main sources of conflict among the civilian and military organizations. Thus, in this study we use OIPT to explain how the information-processing capability of the organization under moderating effect of organizational culture can build swift trust and further improve collaboration. These empirical results highlight the areas of organizational capability development that appear to be needed for the full exploitation of analytics capability. Furthermore, the results suggest that the importance of complementary capability developments depends on the organizational culture, within which an organization operates during emergencies to build trust and improve collaboration. We hope that this study can serve as a vehicle to advance humanitarian operations management literature.

\section{Appendix A. Operationalization of Constructs}

\begin{tabular}{|c|c|c|}
\hline Construct and Derivation & Types & Measures \\
\hline $\begin{array}{l}\text { Big Data Analytics Capability (BDAC) } \\
\text { (George et al., 2014; Srinivasan and Swink, } \\
\text { 2018) }\end{array}$ & Reflective & $\begin{array}{l}\text { Use of Advanced analytical techniques (e.g. simulation, optimization, regression) to improve decision-making } \\
\text { (BDAC1) } \\
\text { Use of multiple data sources to improve decision-making (BDAC2) } \\
\text { Use of data visualization techniques (e.g. dashboards) to assist users to decision-maker in understanding complex } \\
\text { information (BDAC3) } \\
\text { Dashboards help to display information to undertake cause analysis and continuous improvement (BDAC4) } \\
\text { Deployment of dashboard applications/information in the communication devices (e.g. smart phones, computers) } \\
\text { of the humanitarian actors (BDAC5) }\end{array}$ \\
\hline Swift Trust (Robert et al., 2009) & Reflective & $\begin{array}{l}\text { Colleagues are trustworthy (ST1) } \\
\text { No reason to doubt each other's competence and preparation for the task (ST2) } \\
\text { While working together on specific task, I believe I can rely on them not to cause trouble by careless work (ST3) }\end{array}$ \\
\hline $\begin{array}{l}\text { Collaborative Performance (Krishnan et al., 2006; } \\
\text { Moshtari, 2016) }\end{array}$ & Reflective & $\begin{array}{l}\text { The objectives for which the collaboration was established are being met (CP1) } \\
\text { Our organization is satisfied with the overall performance of the collaboration (CP2) } \\
\text { Our association with these partners has been successful one (CP3) } \\
\text { These partners seems to be satisfied with the overall performance of the collaboration (CP4) }\end{array}$ \\
\hline Flexible Orientation (adapted from Liu et al., 2010) & Reflective & $\begin{array}{l}\text { Less formal structure (flat structure) (FO1) } \\
\text { Less focus on traditions (FO2) } \\
\text { Our organization believes in equality and merit (FO3) } \\
\text { Commitment to innovation and development holds the organizations together (FO4) } \\
\text { Less concerns for security (FO5) }\end{array}$ \\
\hline Control Orientation (adapted from Liu et al., 2010) & Reflective & $\begin{array}{l}\text { Highly structured, hierarchical and oriented toward chains of command (CO1) } \\
\text { Loyalty and tradition holds our organization together (CO2) } \\
\text { Our organization respect age, experience and seniority (CO3) } \\
\text { Focused on attaining mission goals (both explicit and implied) (CO4) } \\
\text { Trained to be secretive for operational security (CO5) }\end{array}$ \\
\hline Temporal Orientation (Moshtari, 2016) & Reflective & $\begin{array}{l}\text { Long-term goals in their relationship (TO1) } \\
\text { Partners expect to work together for a long time (TO2) } \\
\text { Participating organizations concentrate their attention on issues that will affect targets beyond the next (TO3) }\end{array}$ \\
\hline Interdependency (Brown et al., 1995) & Reflective & $\begin{array}{l}\text { It would be costly for our organization to lose its collaboration with the partner (I1) } \\
\text { This partner would find it costly to lose the collaboration with our organization (I2) }\end{array}$ \\
\hline
\end{tabular}

\section{Appendix B. Questionnaire}

Questionnaire ID:

This study is being carried out to gain insight about impact of big data analytics (BDA) capability on swift-trust and collaborative performance among disaster relief actors engaged in disaster relief efforts. Collected data will be used only for academic purposes. We request your cooperation to spare 15-20 min to complete this survey. Thank you.

Name

Name of the Organization.

Designation.

Gender (M/F).

Experience (Years).

E-mail.. 
Instructions: Listed below are dimensions of big data analytics, swift-trust, collaborative performance, flexible orientation, control orientation, temporal orientation and interdependency that may be applicable to your organization. Using the scale provided, please indicate your preference by selecting the relevant option.

\author{
(1) Strongly Disagree \\ (2) Disagree \\ (3) Neither Agree nor Disagree \\ (4) Agree \\ (5) Strongly Agree
}

\begin{tabular}{|c|c|c|c|c|c|c|}
\hline \multirow{2}{*}{$\begin{array}{l}\text { Indicator } \\
\text { BDACl }\end{array}$} & \multirow{2}{*}{$\begin{array}{l}\text { Survey Question } \\
\text { Our organization use advanced analytical techniques (e.g. simulation, optimization, regression) to improve decision-making }\end{array}$} & \multicolumn{5}{|c|}{ Rating } \\
\hline & & 1 & 2 & 3 & 4 & 5 \\
\hline BDAC2 & Our organization use multiple data sources to improve decision-making & 1 & 2 & 3 & 4 & 5 \\
\hline BDAC3 & Our organization use data visualization techniques (e.g. dashboards) to assist users to decision-maker in understanding complex information & 1 & 2 & 3 & 4 & 5 \\
\hline BDAC4 & Our organization use dashboards helps to display information to undertake cause analysis and continuous improvement & 1 & 2 & 3 & 4 & 5 \\
\hline BDAC5 & Our organization use dashboard applications/information in the communication devices (e.g. smart phones, computers) of the humanitarian actors & 1 & 2 & 3 & 4 & 5 \\
\hline ST1 & Our colleagues are trustworthy & 1 & 2 & 3 & 4 & 5 \\
\hline ST2 & I have no reason to doubt each other's competence and preparation for the task & 1 & 2 & 3 & 4 & 5 \\
\hline ST3 & While working together on specific task, I believe I can rely on them not to cause trouble by careless work & 1 & 2 & 3 & 4 & 5 \\
\hline CP1 & The objectives for which the collaboration was established are being met & 1 & 2 & 3 & 4 & 5 \\
\hline CP2 & Our organization is satisfied with the overall performance of the collaboration & 1 & 2 & 3 & 4 & 5 \\
\hline CP3 & Our association with these partners has been successful one & 1 & 2 & 3 & 4 & 5 \\
\hline CP4 & Our partners seems to be satisfied with the overall performance of the collaboration & 1 & 2 & 3 & 4 & 5 \\
\hline FO1 & We have less formal structure (flat structure) & 1 & 2 & 3 & 4 & 5 \\
\hline FO2 & We focus less on traditions & 1 & 2 & 3 & 4 & 5 \\
\hline FO3 & Our organization believes in equality and merit & 1 & 2 & 3 & 4 & 5 \\
\hline FO4 & Commitment to innovation and development holds our organization together & 1 & 2 & 3 & 4 & 5 \\
\hline FO5 & We are less concerned for security & 1 & 2 & 3 & 4 & 5 \\
\hline $\mathrm{CO1}$ & Highly structured, hierarchical and oriented toward chains of command & 1 & 2 & 3 & 4 & 5 \\
\hline $\mathrm{CO} 2$ & Loyalty and tradition holds our organization together & 1 & 2 & 3 & 4 & 5 \\
\hline $\mathrm{CO} 3$ & Our organization respect age, experience and seniority & 1 & 2 & 3 & 4 & 5 \\
\hline $\mathrm{CO} 4$ & We are focused on attaining mission goals (both explicit and implied) & 1 & 2 & 3 & 4 & 5 \\
\hline CO5 & We are trained to be secretive for operational security & 1 & 2 & 3 & 4 & 5 \\
\hline T01 & We have long-term goals in our relationship & 1 & 2 & 3 & 4 & 5 \\
\hline TO2 & We expect partners to work together for a long time & 1 & 2 & 3 & 4 & 5 \\
\hline TO3 & We concentrate our attention on issues that will affect targets beyond the next & 1 & 2 & 3 & 4 & 5 \\
\hline I1 & It would be costly for our organization to lose its collaboration with the partner & 1 & 2 & 3 & 4 & 5 \\
\hline $\mathrm{I} 2$ & Our partner would find it costly to lose the collaboration with our organization & 1 & 2 & 3 & 4 & 5 \\
\hline
\end{tabular}

Appendix C. Profile of responding organizations $(\mathrm{N}=373)$

\begin{tabular}{|c|c|c|}
\hline Organizations & Frequency & Percentage \\
\hline Military forces of different nations & 136 & 36.46 \\
\hline Developed-country government aid agencies & 112 & 30.03 \\
\hline International NGOs & 56 & 15.01 \\
\hline Volunteer, university and faith-based teams and individuals & 46 & 12.33 \\
\hline Service providers and contractors & 23 & 6.17 \\
\hline Nationality & Frequency & Percentage \\
\hline \multicolumn{3}{|l|}{ Asia } \\
\hline Afghanistan & 6 & 1.61 \\
\hline Bangladesh & 11 & 2.95 \\
\hline China & 37 & 9.92 \\
\hline DPR Korea & 6 & 1.61 \\
\hline India & 27 & 7.24 \\
\hline Indonesia & 3 & 0.80 \\
\hline Japan & 21 & 5.63 \\
\hline Myanmar & 4 & 1.07 \\
\hline Thailand & 5 & 1.34 \\
\hline \multicolumn{3}{|l|}{ Europe } \\
\hline Belgium & 8 & 2.14 \\
\hline Denmark & 9 & 2.41 \\
\hline France & 16 & 4.29 \\
\hline Finland & 12 & 3.22 \\
\hline Ireland & 9 & 2.41 \\
\hline Netherlands & 9 & 2.41 \\
\hline United Kingdom & 14 & 3.75 \\
\hline \multicolumn{3}{|l|}{ Africa } \\
\hline Cameroon & 11 & 2.95 \\
\hline Egypt & 8 & 2.14 \\
\hline Niger & 6 & 1.61 \\
\hline Nigeria & 4 & 1.07 \\
\hline Somalia & 3 & 0.80 \\
\hline
\end{tabular}




South Africa
North America
Canada
United States
Mexico
South America
Argentina
Brazil
Chile
Peru

$\begin{array}{ll}13 & 3.49 \\ 23 & \\ 47 & 6.17 \\ 7 & 12.60 \\ & 1.88 \\ 8 & \\ 21 & 2.14 \\ 11 & 5.63 \\ 14 & 2.95 \\ & \\ \end{array}$

Appendix D. Model fit and quality indices $(\mathrm{N}=373)$

\begin{tabular}{|c|c|c|c|}
\hline Model fit and quality indices & Value from analysis & Acceptable if & Reference \\
\hline APC & $0.362, p=0.001$ & $\mathrm{p}<0.05$ & Rosenthal and Rosnow (1991) \\
\hline ARS & $0.840, \mathrm{p}<0.001$ & $\mathrm{p}<0.05$ & \\
\hline AVIF & $0.298, \mathrm{p}<0.001$ & $\mathrm{p}<0.05$ & Kock (2015b) \\
\hline Tenenhaus GoF & 0.550 & Large if $\geq 0.36$ & Tenenhaus et al. (2005) \\
\hline
\end{tabular}

Appendix E. Descriptive Statistics

\begin{tabular}{|c|c|c|c|c|c|c|c|}
\hline & & \multirow[t]{3}{*}{ Statistic } & \multirow[t]{3}{*}{ Std. Error } & \multicolumn{4}{|l|}{ Bootstrap } \\
\hline & & & & \multirow[t]{2}{*}{ Bias } & \multirow[t]{2}{*}{ Std. Error } & \multicolumn{2}{|c|}{ 95\% Confidence Interval } \\
\hline & & & & & & Lower & Upper \\
\hline \multirow[t]{7}{*}{ BDAC1 } & $\mathrm{N}$ & 373 & & 0 & 0 & 373 & 373 \\
\hline & Minimum & 2.00 & & & & & \\
\hline & Maximum & 4.00 & & & & & \\
\hline & Mean & 2.9625 & & 0.0001 & 0.0386 & 2.8847 & 3.0349 \\
\hline & Std. Deviation & 0.75753 & & -0.00154 & 0.01714 & 0.71989 & 0.78943 \\
\hline & Skewness & 0.063 & 0.126 & 0.000 & 0.064 & -0.061 & 0.193 \\
\hline & Kurtosis & -1.252 & 0.252 & 0.012 & 0.081 & -1.387 & -1.063 \\
\hline \multirow[t]{7}{*}{ BDAC2 } & $\mathrm{N}$ & 373 & & 0 & 0 & 373 & 373 \\
\hline & Minimum & 2.00 & & & & & \\
\hline & Maximum & 4.00 & & & & & \\
\hline & Mean & 2.9759 & & -0.0008 & 0.0387 & 2.8955 & 3.0483 \\
\hline & Std. Deviation & 0.74916 & & -0.00107 & 0.01695 & 0.71547 & 0.78242 \\
\hline & Skewness & 0.039 & 0.126 & 0.001 & 0.063 & -0.077 & 0.171 \\
\hline & Kurtosis & -1.213 & 0.252 & 0.010 & 0.082 & -1.360 & -1.036 \\
\hline \multirow[t]{7}{*}{ BDAC3 } & $\mathrm{N}$ & 373 & & 0 & 0 & 373 & 373 \\
\hline & Minimum & 2.00 & & & & & \\
\hline & Maximum & 4.00 & & & & & \\
\hline & Mean & 3.0992 & & -0.0009 & 0.0397 & 3.0188 & 3.1769 \\
\hline & Std. Deviation & 0.78173 & & -0.00144 & 0.01628 & 0.74781 & 0.81207 \\
\hline & Skewness & -0.175 & 0.126 & 0.002 & 0.071 & -0.314 & -0.033 \\
\hline & Kurtosis & -1.343 & 0.252 & 0.011 & 0.073 & -1.470 & -1.181 \\
\hline \multirow[t]{7}{*}{ BDAC4 } & $\mathrm{N}$ & 373 & & 0 & 0 & 373 & 373 \\
\hline & Minimum & 2.00 & & & & & \\
\hline & Maximum & 4.00 & & & & & \\
\hline & Mean & 2.8686 & & 0.0010 & 0.0412 & 2.7856 & 2.9491 \\
\hline & Std. Deviation & 0.74155 & & -0.00047 & 0.01716 & 0.70587 & 0.77308 \\
\hline & Skewness & 0.215 & 0.126 & -0.002 & 0.069 & 0.085 & 0.351 \\
\hline & Kurtosis & -1.156 & 0.252 & 0.006 & 0.084 & -1.308 & -0.975 \\
\hline \multirow[t]{7}{*}{ BDAC5 } & $\mathrm{N}$ & 373 & & 0 & 0 & 373 & 373 \\
\hline & Minimum & 1.00 & & & & & \\
\hline & Maximum & 5.00 & & & & & \\
\hline & Mean & 3.1635 & & 0.0020 & 0.0461 & 3.0778 & 3.2600 \\
\hline & Std. Deviation & 0.90551 & & -0.00141 & 0.03140 & 0.84442 & 0.96541 \\
\hline & Skewness & 0.239 & 0.126 & -0.003 & 0.084 & 0.081 & 0.407 \\
\hline & Kurtosis & -0.266 & 0.252 & -0.001 & 0.150 & -0.539 & 0.059 \\
\hline \multirow[t]{7}{*}{ ST1 } & $\mathrm{N}$ & 373 & & 0 & 0 & 373 & 373 \\
\hline & Minimum & 1.00 & & & & & \\
\hline & Maximum & 5.00 & & & & & \\
\hline & Mean & 3.3003 & & -0.0024 & 0.0503 & 3.1958 & 3.3995 \\
\hline & Std. Deviation & 0.96772 & & -0.00401 & 0.03057 & 0.90438 & 1.02424 \\
\hline & Skewness & -0.256 & 0.126 & 0.006 & 0.091 & -0.427 & -0.080 \\
\hline & Kurtosis & -0.353 & 0.252 & -0.001 & 0.134 & -0.602 & -0.075 \\
\hline \multirow[t]{6}{*}{ ST2 } & $\mathrm{N}$ & 373 & & 0 & 0 & 373 & 373 \\
\hline & Minimum & 1.00 & & & & & \\
\hline & Maximum & 5.00 & & & & & \\
\hline & Mean & 3.4102 & & 0.0005 & 0.0461 & 3.3164 & 3.5013 \\
\hline & Std. Deviation & 0.89238 & & -0.00259 & 0.03484 & 0.82254 & 0.96021 \\
\hline & Skewness & -0.446 & 0.126 & 0.011 & 0.112 & -0.645 & -0.204 \\
\hline
\end{tabular}




\begin{tabular}{|c|c|c|c|c|c|c|c|}
\hline & Kurtosis & 0.292 & 0.252 & -0.016 & 0.191 & -0.086 & 0.678 \\
\hline \multirow[t]{7}{*}{ ST3 } & $\mathrm{N}$ & 373 & & 0 & 0 & 373 & 373 \\
\hline & Minimum & 1.00 & & & & & \\
\hline & Maximum & 5.00 & & & & & \\
\hline & Mean & 3.3458 & & -0.0013 & 0.0494 & 3.2440 & 3.4424 \\
\hline & Std. Deviation & 0.92514 & & -0.00046 & 0.03339 & 0.85549 & 0.98927 \\
\hline & Skewness & -0.330 & 0.126 & 0.007 & 0.097 & -0.515 & -0.129 \\
\hline & Kurtosis & -0.074 & 0.252 & -0.016 & 0.156 & -0.374 & 0.237 \\
\hline \multirow[t]{7}{*}{ CP1 } & $\mathrm{N}$ & 373 & & 0 & 0 & 373 & 373 \\
\hline & Minimum & 1.00 & & & & & \\
\hline & Maximum & 5.00 & & & & & \\
\hline & Mean & 3.3807 & & -0.0005 & 0.0476 & 3.2896 & 3.4745 \\
\hline & Std. Deviation & 0.90687 & & -0.00160 & 0.03612 & 0.83702 & 0.97680 \\
\hline & Skewness & -0.587 & 0.126 & 0.006 & 0.101 & -0.784 & -0.385 \\
\hline & Kurtosis & 0.210 & 0.252 & -0.018 & 0.198 & -0.154 & 0.614 \\
\hline \multirow[t]{7}{*}{ CP2 } & $\mathrm{N}$ & 373 & & 0 & 0 & 373 & 373 \\
\hline & Minimum & 2.00 & & & & & \\
\hline & Maximum & 4.00 & & & & & \\
\hline & Mean & 3.1448 & & -0.0015 & 0.0371 & 3.0697 & 3.2171 \\
\hline & Std. Deviation & 0.70364 & & -0.00171 & 0.01895 & 0.66561 & 0.73865 \\
\hline & Skewness & -0.210 & 0.126 & 0.004 & 0.058 & -0.324 & -0.100 \\
\hline & Kurtosis & -0.970 & 0.252 & 0.012 & 0.099 & -1.147 & -0.768 \\
\hline \multirow{7}{*}{ CP3 } & $\mathrm{N}$ & 373 & & 0 & 0 & 373 & 373 \\
\hline & Minimum & 2.00 & & & & & \\
\hline & Maximum & 4.00 & & & & & \\
\hline & Mean & 2.8633 & & -0.0004 & 0.0357 & 2.7910 & 2.9383 \\
\hline & Std. Deviation & 0.71095 & & -0.00164 & 0.01860 & 0.67269 & 0.74609 \\
\hline & Skewness & 0.204 & 0.126 & -0.001 & 0.056 & 0.093 & 0.317 \\
\hline & Kurtosis & -1.008 & 0.252 & 0.012 & 0.096 & -1.184 & -0.804 \\
\hline \multirow[t]{7}{*}{ CP4 } & $\mathrm{N}$ & 373 & & 0 & 0 & 373 & 373 \\
\hline & Minimum & 1.00 & & & & & \\
\hline & Maximum & 5.00 & & & & & \\
\hline & Mean & 2.7185 & & -0.0002 & 0.0360 & 2.6515 & 2.7909 \\
\hline & Std. Deviation & 0.69065 & & -0.00102 & 0.02983 & 0.62982 & 0.74620 \\
\hline & Skewness & 0.092 & 0.126 & -0.011 & 0.170 & -0.255 & 0.395 \\
\hline & Kurtosis & 0.732 & 0.252 & -0.043 & 0.300 & 0.101 & 1.292 \\
\hline F01 & $\mathrm{N}$ & 373 & & 0 & 0 & 373 & 373 \\
\hline & Minimum & 1.00 & & & & & \\
\hline & Maximum & 5.00 & & & & & \\
\hline & Mean & 2.8257 & & 0.0002 & 0.0425 & 2.7399 & 2.9062 \\
\hline & Std. Deviation & 0.81596 & & -0.00004 & 0.03312 & 0.75496 & 0.88247 \\
\hline & Skewness & 0.181 & 0.126 & -0.002 & 0.124 & -0.072 & 0.411 \\
\hline & Kurtosis & 0.445 & 0.252 & -0.024 & 0.196 & 0.070 & 0.812 \\
\hline $\mathrm{FO} 2$ & $\mathrm{~N}$ & 373 & & 0 & 0 & 373 & 373 \\
\hline & Minimum & 1.00 & & & & & \\
\hline & Maximum & 5.00 & & & & & \\
\hline & Mean & 3.0000 & & -0.0007 & 0.0397 & 2.9196 & 3.0804 \\
\hline & Std. Deviation & 0.77944 & & -0.00121 & 0.02997 & 0.72030 & 0.83585 \\
\hline & Skewness & -0.240 & 0.126 & 0.002 & 0.114 & -0.469 & -0.012 \\
\hline & Kurtosis & 0.158 & 0.252 & -0.019 & 0.207 & -0.251 & 0.541 \\
\hline FO3 & $\mathrm{N}$ & 373 & & 0 & 0 & 373 & 373 \\
\hline & Minimum & 1.00 & & & & & \\
\hline & Maximum & 5.00 & & & & & \\
\hline & Mean & 2.8070 & & -0.0004 & 0.0418 & 2.7239 & 2.8900 \\
\hline & Std. Deviation & 0.77616 & & -0.00085 & 0.03453 & 0.70528 & 0.84460 \\
\hline & Skewness & 0.488 & 0.126 & -0.012 & 0.135 & 0.175 & 0.718 \\
\hline & Kurtosis & 0.864 & 0.252 & -0.021 & 0.228 & 0.407 & 1.302 \\
\hline FO4 & $\mathrm{N}$ & 373 & & 0 & 0 & 373 & 373 \\
\hline & Minimum & 1.00 & & & & & \\
\hline & Maximum & 4.00 & & & & & \\
\hline & Mean & 2.6327 & & 0.0020 & 0.0421 & 2.5523 & 2.7239 \\
\hline & Std. Deviation & 0.80101 & & 0.00005 & 0.02521 & 0.75394 & 0.84887 \\
\hline & Skewness & -0.029 & 0.126 & 0.000 & 0.077 & -0.174 & 0.137 \\
\hline & Kurtosis & -0.497 & 0.252 & -0.005 & 0.087 & -0.671 & -0.334 \\
\hline FO5 & $\mathrm{N}$ & 373 & & 0 & 0 & 373 & 373 \\
\hline & Minimum & 1.00 & & & & & \\
\hline & Maximum & 5.00 & & & & & \\
\hline & Mean & 3.0188 & & 0.0027 & 0.0418 & 2.9330 & 3.0992 \\
\hline & Std. Deviation & 0.82447 & & -0.00051 & 0.02795 & 0.77057 & 0.87682 \\
\hline & Skewness & 0.023 & 0.126 & -0.002 & 0.102 & -0.174 & 0.219 \\
\hline & Kurtosis & -0.399 & 0.252 & -0.010 & 0.157 & -0.714 & -0.078 \\
\hline $\mathrm{CO} 1$ & $\mathrm{~N}$ & 373 & & 0 & 0 & 373 & 373 \\
\hline & Minimum & 1.00 & & & & & \\
\hline & Maximum & 5.00 & & & & & \\
\hline & Mean & 2.8713 & & 0.0034 & 0.0501 & 2.7749 & 2.9704 \\
\hline & Std. Deviation & 0.96138 & & -0.00269 & 0.03037 & 0.89914 & 1.01902 \\
\hline & Skewness & -0.178 & 0.126 & -0.009 & 0.084 & -0.353 & -0.018 \\
\hline & Kurtosis & -0.499 & 0.252 & 0.001 & 0.124 & -0.726 & -0.240 \\
\hline $\mathrm{CO} 2$ & $\mathrm{~N}$ & 373 & & 0 & 0 & 373 & 373 \\
\hline & Minimum & 1.00 & & & & & \\
\hline
\end{tabular}




\begin{tabular}{|c|c|c|c|c|c|c|c|}
\hline & \multirow{2}{*}{$\begin{array}{l}\text { Maximum } \\
\text { Mean }\end{array}$} & \multicolumn{2}{|l|}{4.00} & \multirow{2}{*}{0.0021} & \multirow{2}{*}{0.0425} & \multirow{2}{*}{2.6247} & \multirow{2}{*}{2.7855} \\
\hline & & 2.7024 & & & & & \\
\hline & Std. Deviation & 0.83274 & & -0.00139 & 0.02576 & 0.78078 & 0.88349 \\
\hline & Skewness & -0.154 & 0.126 & -0.004 & 0.071 & -0.299 & -0.009 \\
\hline & Kurtosis & -0.548 & 0.252 & 0.006 & 0.099 & -0.721 & -0.344 \\
\hline \multirow[t]{7}{*}{$\mathrm{CO} 3$} & $\mathrm{~N}$ & 373 & & 0 & 0 & 373 & 373 \\
\hline & Minimum & 1.00 & & & & & \\
\hline & Maximum & 5.00 & & & & & \\
\hline & Mean & 3.0322 & & 0.0024 & 0.0446 & 2.9517 & 3.1233 \\
\hline & Std. Deviation & 0.89745 & & -0.00209 & 0.03181 & 0.83105 & 0.95678 \\
\hline & Skewness & 0.026 & 0.126 & -0.003 & 0.096 & -0.162 & 0.223 \\
\hline & Kurtosis & -0.155 & 0.252 & -0.002 & 0.141 & -0.413 & 0.132 \\
\hline \multirow[t]{7}{*}{$\mathrm{CO} 4$} & $\mathrm{~N}$ & 373 & & 0 & 0 & 373 & 373 \\
\hline & Minimum & 1.00 & & & & & \\
\hline & Maximum & 5.00 & & & & & \\
\hline & Mean & 2.9732 & & 0.0031 & 0.0410 & 2.8954 & 3.0563 \\
\hline & Std. Deviation & 0.79605 & & -0.00259 & 0.02828 & 0.73985 & 0.85014 \\
\hline & Skewness & -0.113 & 0.126 & 0.003 & 0.105 & -0.316 & 0.098 \\
\hline & Kurtosis & -0.216 & 0.252 & 0.002 & 0.182 & -0.551 & 0.137 \\
\hline \multirow[t]{7}{*}{$\operatorname{CO} 5$} & $\mathrm{~N}$ & 373 & & 0 & 0 & 373 & 373 \\
\hline & Minimum & 1.00 & & & & & \\
\hline & Maximum & 5.00 & & & & & \\
\hline & Mean & 2.8874 & & 0.0008 & 0.0426 & 2.8044 & 2.9678 \\
\hline & Std. Deviation & 0.84763 & & -0.00202 & 0.02748 & 0.79188 & 0.89886 \\
\hline & Skewness & 0.243 & 0.126 & -0.005 & 0.099 & 0.037 & 0.431 \\
\hline & Kurtosis & -0.482 & 0.252 & -0.014 & 0.153 & -0.797 & -0.169 \\
\hline \multirow[t]{7}{*}{ T01 } & $\mathrm{N}$ & 373 & & 0 & 0 & 373 & 373 \\
\hline & Minimum & 2.00 & & & & & \\
\hline & Maximum & 5.00 & & & & & \\
\hline & Mean & 3.0804 & & 0.0001 & 0.0386 & 3.0027 & 3.1608 \\
\hline & Std. Deviation & 0.73978 & & -0.00166 & 0.02406 & 0.68793 & 0.78580 \\
\hline & Skewness & 0.232 & 0.126 & -0.002 & 0.088 & 0.061 & 0.407 \\
\hline & Kurtosis & -0.334 & 0.252 & 0.002 & 0.184 & -0.681 & 0.049 \\
\hline \multirow[t]{7}{*}{ TO2 } & $\mathrm{N}$ & 373 & & 0 & 0 & 373 & 373 \\
\hline & Minimum & 1.00 & & & & & \\
\hline & Maximum & 5.00 & & & & & \\
\hline & Mean & 3.0885 & & -0.0006 & 0.0463 & 3.0000 & 3.1795 \\
\hline & Std. Deviation & 0.88305 & & -0.00071 & 0.03440 & 0.81210 & 0.94942 \\
\hline & Skewness & 0.156 & 0.126 & -0.001 & 0.101 & -0.032 & 0.364 \\
\hline & Kurtosis & 0.108 & 0.252 & 0.000 & 0.176 & -0.203 & 0.476 \\
\hline \multirow[t]{7}{*}{ TO3 } & $\mathrm{N}$ & 373 & & 0 & 0 & 373 & 373 \\
\hline & Minimum & 1.00 & & & & & \\
\hline & Maximum & 5.00 & & & & & \\
\hline & Mean & 3.1180 & & 0.0003 & 0.0404 & 3.0402 & 3.2011 \\
\hline & Std. Deviation & 0.78427 & & -0.00283 & 0.02872 & 0.72296 & 0.83721 \\
\hline & Skewness & -0.211 & 0.126 & 0.007 & 0.113 & -0.419 & 0.017 \\
\hline & Kurtosis & 0.041 & 0.252 & -0.006 & 0.201 & -0.336 & 0.466 \\
\hline \multirow[t]{7}{*}{ I1 } & $\mathrm{N}$ & 373 & & 0 & 0 & 373 & 373 \\
\hline & Minimum & 1.00 & & & & & \\
\hline & Maximum & 5.00 & & & & & \\
\hline & Mean & 3.0402 & & -0.0008 & 0.0368 & 2.9705 & 3.1126 \\
\hline & Std. Deviation & 0.71916 & & -0.00111 & 0.02884 & 0.66011 & 0.77424 \\
\hline & Skewness & -0.278 & 0.126 & 0.003 & 0.125 & -0.510 & -0.011 \\
\hline & Kurtosis & 0.339 & 0.252 & 0.012 & 0.245 & -0.116 & 0.866 \\
\hline \multirow[t]{7}{*}{ I2 } & $\mathrm{N}$ & 373 & & 0 & 0 & 373 & 373 \\
\hline & Minimum & 1.00 & & & & & \\
\hline & Maximum & 5.00 & & & & & \\
\hline & Mean & 3.1180 & & 0.0006 & 0.0405 & 3.0402 & 3.1984 \\
\hline & Std. Deviation & 0.79110 & & -0.00145 & 0.02881 & 0.73697 & 0.84915 \\
\hline & Skewness & -0.180 & 0.126 & 0.000 & 0.120 & -0.405 & 0.055 \\
\hline & Kurtosis & 0.031 & 0.252 & -0.001 & 0.199 & -0.350 & 0.463 \\
\hline
\end{tabular}

Appendix F. Goodness of fit Statistics

Model 1: Loadings freely estimated Model 2: Loadings constrained to be equal

\begin{tabular}{llll}
\hline$\chi^{2} / \mathrm{df}$ & 21 & 18 & 16 \\
CFI & 0.95 & 0.94 & 0.97 \\
RMSEA & 0.03 & 0.04 & 0.029 \\
SRMR within & 0.032 & 0.036 & 0.039 \\
SRMR between & 0.092 & 0.312 & 0.317 \\
\hline
\end{tabular}

0.039
Model 3: Loadings constrained to be equal and residual variances constrained to zero

0.97
0.029
0.039 


\section{References}

Agarwal, R., Dhar, V., 2014. Big data, data science, and analytics: the opportunity and challenge for IS research. Inf. Syst. Res. 25 (3), 443-448.

Akhtar, P., Marr, N.E., Garnevska, E.V., 2012. Coordination in humanitarian relief chains: chain coordinators. J. Humanit. Logist. Supply Chain Manag. 2 (1), 85-103.

Akter, S., Wamba, S.F., Gunasekaran, A., Dubey, R., Childe, S.J., 2016. How to improve firm performance using big data analytics capability and business strategy alignment? Int. J. Prod. Econ. 182, 113-131.

Akter, S., Fosso Wamba, S., Dewan, S., 2017. Why PLS-SEM is suitable for complex modelling? An empirical illustration in big data analytics quality. Prod. Plann. Contr. 28 (11-12), 1011-1021.

Altay, N., Pal, R., 2014. Information diffusion among agents: implications for humanitarian operations. Prod. Oper. Manag. 23 (6), 1015-1027.

Altay, N., Labonte, M., 2014. Challenges in humanitarian information management and exchange: evidence from Haiti. Disasters 38 (S1), 50-72.

Armstrong, J.S., Overton, T.S., 1977. Estimating nonresponse bias in mail surveys. J. Market. Res. 14 (3), 396-402.

Bagozzi, R.P., Yi, Y., Nassen, K.D., 1998. Representation of measurement error in marketing variables: review of approaches and extension to three-facet designs. J. Econom. 89 (1-2), 393-421.

Balakrishnan, A., Geunes, J., 2004. Collaboration and coordination in supply chain management and E-commerce. Prod. Oper. Manag. 13 (1), 1-2.

Balcik, B., Beamon, B.M., Krejci, C.C., Muramatsu, K.M., Ramirez, M., 2010. Coordination in humanitarian relief chains: practices, challenges and opportunities. Int. J. Prod. Econ. 126 (1), 22-34.

Barber, E., 2011. Military involvement in humanitarian supply chains (chapter 8). In: Kovacs, G., Spens, K. (Eds.), Relief Supply Chain Management for Disasters: Humanitarian Aid and Emergency Logistics. IGI Global, Hershey, US.

Barratt, M., 2004. Understanding the meaning of collaboration in the supply chain. Supply Chain Manag. Int. J. 9 (1), 30-42.

Barratt, M., Oke, A., 2007. Antecedents of supply chain visibility in retail supply chains: a resource-based theory perspective. J. Oper. Manag. 25 (6), 1217-1233.

Bentler, P.M., 1992. On the fit of models to covariances and methodology to the Bulletin. Psychol. Bull. 112 (3), 400-404.

Bowersox, D.J., Closs, D.J., Stank, T.P., 2003. How to master cross-enterprise collaboration. Supply Chain Manag. Rev. 7 (4), 18-27.

Boin, A., Kelle, P., Whybark, D.C., 2010. Resilient supply chains for extreme situations: outlining a new field of study. Int. J. Prod. Econ. 126 (1), 1-6.

Bottoni, G., 2018. A multilevel measurement model of social cohesion. Soc. Indicat. Res. 136 (3), 835-857.

Boyd, B.K., Takacs Haynes, K., Hitt, M.A., Bergh, D.D., Ketchen Jr., D.J., 2012. Contingency hypotheses in strategic management research: use, disuse, or misuse? J. Manag. 38 (1), 278-313.

Boyer, K.K., Verma, R., 2000. Multiple raters in survey-based operations management research: a review and tutorial. Prod. Oper. Manag. 9 (2), 128-140.

Brown, J.R., Lusch, R.F., Nicholson, C.Y., 1995. Power and relationship commitment: their impact on marketing channel member performance. J. Retailing 71 (4), 363-392.

Cadilhon, J.J., Fearne, A.P., Thi Giac Tam, P., Moustier, P., Poole, N.D., 2005. Collaborative commerce or just common sense? Insights from vegetable supply chains in Ho Chi Minh City. Supply Chain Manag. Int. J. 10 (3), 147-149.

Cameron, K.S., Quinn, R.E., 2011. Diagnosing and Changing Organizational Culture: Based on the Competing Values Framework. John Wiley \& Sons.

Cao, M., Zhang, Q., 2011. Supply chain collaboration: impact on collaborative advantage and firm performance. J. Oper. Manag. 29 (3), 163-180.

Chen, I.J., Paulraj, A., 2004. Towards a theory of supply chain management: the constructs and measurements. J. Oper. Manag. 22 (2), 119-150.

Chin, W.W., 1998. Commentary: issues and opinion on structural equation modeling. MIS Q. 22 (1) Vii-Xvi.

Davis, L.B., Samanlioglu, F., Qu, X., Root, S., 2013. Inventory planning and coordination in disaster relief efforts. Int. J. Prod. Econ. 141 (2), 561-573.

de Camargo, J.A., Mendonça, P.S.M., de Oliveira, J.H.C., Jabbour, C.J.C., de Sousa Jabbour, A.B.L., 2017. Giving voice to the silent: a framework for understanding stakeholders' participation in socially-oriented initiatives, community-based actions and humanitarian operations projects. Ann. Oper. Res. 1-16.

Deshpandé, R., Farley, J.U., Webster Jr., F.E., 1993. Corporate culture, customer orientation, and innovativeness in Japanese firms: a quadrad analysis. J. Market. 57 (1), $23-37$.

DeVellis, R.F., 1991. Scale Development: Theory and Applications. Sage Publications, Newbury Park, CA.

Dillman, D.A., 2007. Mail and Internet Surveys: the Tailored Design. Wiley, NJ.

Dowty, R.A., Wallace, W.A., 2010. Implications of organizational culture for supply chain disruption and restoration. Int. J. Prod. Econ. 126 (1), 57-65.

Dubey, R., Altay, N., Blome, C., 2017a. Swift trust and commitment: the missing links for humanitarian supply chain coordination? Ann. Oper. Res. 1-19.

Dubey, R., Gunasekaran, A., Childe, S.J., Papadopoulos, T., Hazen, B., Giannakis, M., Roubaud, D., 2017b. Examining the effect of external pressures and organizational culture on shaping performance measurement systems (PMS) for sustainability benchmarking: some empirical findings. Int. J. Prod. Econ. 193, 63-76.

Dubey, R., Luo, Z., Gunasekaran, A., Akter, S., Hazen, B.T., Douglas, M.A., 2018a. Big data and predictive analytics in humanitarian supply chains: enabling visibility and coordination in the presence of swift trust. Int. J. Logist. Manag. 29 (2), 485-512.

Dubey, R., Gunasekaran, A., Childe, S.J., 2018b. Big data analytics capability in supply chain agility: the moderating effect of organizational flexibility. Manag. Decis.
https://doi.org/10.1108/MD-01-2018-0119.

Durugbo, C., 2015. Modelling information for collaborative networks. Prod. Plann. Contr. 26 (1), 34-52

Dwivedi, Y.K., Kapoor, K.K., Williams, M.D., Williams, J., 2013. RFID systems in libraries: an empirical examination of factors affecting system use and user satisfaction. Int. J. Inf. Manag. 33 (2), 367-377.

Dwivedi, Y.K., Shareef, M.A., Mukerji, B., Rana, N.P., Kapoor, K.K., 2017. Involvement in emergency supply chain for disaster management: a cognitive dissonance perspective. Int. J. Prod. Res. 1-16.

Eckstein, D., Goellner, M., Blome, C., Henke, M., 2015. The performance impact of supply chain agility and supply chain adaptability: the moderating effect of product complexity. Int. J. Prod. Res. 53 (10), 3028-3046.

Egnell, R., 2006. Explaining US and British performance in complex expeditionary operations: the civil-military dimension. J. Strat. Stud. 29 (6), 1041-1075.

Ergun, O., Gui, L., Heier Stamm, J.L., Keskinocak, P., Swann, J., 2014. Improving humanitarian operations through technology-enabled collaboration. Prod. Oper. Manag. 23 (6), 1002-1014.

Fan, H., Li, G., Sun, H., Cheng, T.C.E., 2017. An information processing perspective on supply chain risk management: antecedents, mechanism, and consequences. Int. J. Prod. Econ. 185, 63-75.

Fawcett, S.E., Jones, S.L., Fawcett, A.M., 2012. Supply chain trust: the catalyst for collaborative innovation. Bus. Horiz. 55 (2), 163-178.

Fawcett, A.M., Fawcett, S.E., 2013. Benchmarking the state of humanitarian aid and disaster relief: a systems design perspective and research agenda. Benchmarking Int. J. 20 (5), 661-692.

Fawcett, S.E., McCarter, M.W., Fawcett, A.M., Webb, G.S., Magnan, G.M., 2015. Why supply chain collaboration fails: the socio-structural view of resistance to relational strategies. Supply Chain Manag.: Int. J. 20 (6), 648-663.

Fornell, C., Larcker, D.F., 1981. Evaluating structural equation models with unobservable variables and measurement error. J. Market. Res. 18 (1), 39-50.

Fosso Wamba, S., Akter, S., Edwards, A., Chopin, G., Gnanzou, D., 2015. How 'big data' can make big impact: findings from a systematic review and a longitudinal case study. Int. J. Prod. Econ. 165, 234-246.

Fosso Wamba, S., Gunasekaran, A., Akter, S., Ren, S.J., Dubey, R., Childe, S.J., 2017. Big data analytics and firm performance: effects of dynamic capabilities. J. Bus. Res. 70, $356-365$.

Galbraith, J.R., 1973. Designing Complex Organizations. Addison-Wesley, Reading, MA.

Galbraith, J.R., 1974. Organization design: an information processing view. Interfaces 4 (3), 28-36.

Galbraith, J.R., 1977. Organization Design. Addison Wesley Publishing Company, Reading, MA.

Galbraith, J.R., 2014. Organizational design challenges resulting from big data. J. Org. Des. 3 (1), 2-13.

George, G., Haas, M.R., Pentland, A., 2014. Big data and management. Acad. Manag. J. 57 (2), 321-326.

Gillmann, N., 2009. Interagency coordination during disaster strategic choices for the UN. In: NGOs, and Other Humanitarian Actors in the Field, Baden-Baden: Nomos.

Giorgi, S., Lockwood, C., Glynn, M.A., 2015. The many faces of culture: making sense of 30 years of research on culture in organization studies. Acad. Manag. Ann. 9 (1), $1-54$.

Goldstein, H., 1987. Multilevel Models in Education and Social Research. Oxford University Press, New York.

Golicic, S.L., Foggin, J.H., Mentzer, J.T., 2003. Relationship magnitude and its role in interorganizational relationship structure. J. Bus. Logist. 24 (1), 57-75.

Goodman, R.A., Goodman, L.P., 1976. Some management issues in temporary systems: a study of professional development and manpower-the theater case. Adm. Sci. Q. 21 (3), 494-501.

Goswami, S., Chakraborty, S., Ghosh, S., Chakrabarti, A., Chakraborty, B., 2018. A review on application of data mining techniques to combat natural disasters. Ain Shams Eng. J. 9 (3), 365-378.

Gölzer, P., Fritzsche, A., 2017. Data-driven operations management: organisational implications of the digital transformation in industrial practice. Prod. Plann. Contr. 28 (16), 1332-1343.

Guide, V.D.R., Ketokivi, M., 2015. Notes from the Editors: redefining some methodological criteria for the journal. J. Oper. Manag. 37 v-viii).

Gulati, R., Singh, H., 1998. The architecture of cooperation: managing coordination costs and appropriation concerns in strategic alliances. Adm. Sci. Q. 781-814.

Gulati, R., Puranam, P., Tushman, M., 2012. Meta-organization design: rethinking design in interorganizational and community contexts. Strat. Manag. J. 33 (6), 571-586.

Gupta, M., George, J.F., 2016. Toward the development of a big data analytics capability. Inf. Manag. 53 (8), 1049-1064.

Hazen, B.T., Boone, C.A., Ezell, J.D., Jones-Farmer, L.A., 2014. Data quality for data science, predictive analytics, and big data in supply chain management: an introduction to the problem and suggestions for research and applications. Int. J. Prod. Econ. 154, 72-80.

Heaslip, G., Mangan, J., Lalwani, C., 2008. Modelling a Humanitarian Supply Chain Using the Structured Analysis and Design Technique (SADT). Logistics Research Network (LRN). http://eprints.maynoothuniversity.ie/2534/, Accessed date: 25 May 2016.

Heaslip, G., 2011. Challenges of civil military cooperation/coordination in humanitarian relief (chapter 9). In: Kovacs, G., Spens, K. (Eds.), Relief Supply Chain Management for Disasters: Humanitarian Aid and Emergency Logistics. IGI Global, Hershey, US.

Heaslip, G., Sharif, A.M., Althonayan, A., 2012. Employing a systems-based perspective to the identification of inter-relationships within humanitarian logistics. Int. J. Prod. Econ. 139 (2), 377-392.

Heaslip, G., Barber, E., 2014. Using the military in disaster relief: systemising challenges and opportunities. J. Humanit. Logist. Supply Chain Manag. 4 (1), 60-81. 
Henseler, J., Dijkstra, T.K., Sarstedt, M., Ringle, C.M., Diamantopoulos, A., Straub, D.W., Calantone, R.J., 2014. Common beliefs and reality about PLS: comments on rönkkö and evermann (2013). Organ. Res. Methods 17 (2), 182-209.

Hoffman, N., Klepper, R., 2000. Assimilating new technologies: the role of organizational culture. Inf. Syst. Manag. 17 (3), 36-42.

Hox, J.J., 2013. Multilevel regression and multilevel structural equation modeling. Oxf. Handb. Quant. Methods 2 (1), 281-294.

Hox, J.J., Moerbeek, M., Van de Schoot, R., 2017. Multilevel Analysis: Techniques and Applications. Routledge.

Hyllengren, P., Larsson, G., Fors, M., Sjöberg, M., Eid, J., Kjellevold Olsen, O., 2011. Swift trust in leaders in temporary military groups. Team Perform. Manag.: Int. J. 17 (7/8), 354-368.

Inemek, A., Matthyssens, P., 2013. The impact of buyer-supplier relationships on supplier innovativeness: an empirical study in cross-border supply networks. Ind. Market. Manag. 42 (4), 580-594.

International Peace Institute, 2013. Peacekeeping Reimbursements: Key Topics for the Next COE Working Group. pp. 1-12. (Date of access, 14th August, 2016). https:// www.ipinst.org/wp-content/uploads/publications/ipi_e_pub_peacekeeping_reimb_ ib_2_.pdf.

Jabbour, C.J.C., Sobreiro, V.A., de Sousa Jabbour, A.B.L., de Souza Campos, L.M., Mariano, E.B., Renwick, D.W.S., 2017. An analysis of the literature on humanitarian logistics and supply chain management: paving the way for future studies. Ann. Oper. Res. 1-19.

James, L.R., Demaree, R.G., Wolf, G., 1984. Estimating within-group interrater reliability with and without response bias. J. Appl. Psychol. 69 (1), 85.

Janssen, M., Lee, J., Bharosa, N., Cresswell, A., 2010. Advances in multi-agency disaster management: key elements in disaster research. Inf. Syst. Front 12 (1), 1-7.

Kabra, G., Ramesh, A., 2015. Analyzing drivers and barriers of coordination in humanitarian supply chain management under fuzzy environment. Benchmarking Int. J. 22 (4), 559-587.

Ketokivi, M.A., Schroeder, R.G., 2004. Perceptual measures of performance: fact or fiction? J. Oper. Manag. 22 (3), 247-264.

Khazanchi, S., Lewis, M.W., Boyer, K.K., 2007. Innovation-supportive culture: the impact of organizational values on process innovation. J. Oper. Manag, 25 (4), 871-884.

Kim, C., Oh, E., Shin, N., Chae, M., 2009. An empirical investigation of factors affecting ubiquitous computing use and U-business value. Int. J. Inf. Manag. 29 (6), 436-448.

Kitchell, S., 1995. Corporate culture, environmental adaptation, and innovation adoption: a qualitative/quantitative approach. J. Acad. Market. Sci. 23 (3), 195-205.

Kock, N., 2015a. A note on how to conduct a factor-based PLS-SEM analysis. Int. J. eCollaboration 11 (3), 1-9.

Kock, N., 2015b. WarpPLS 5.0 User Manual. 2015. ScriptWarp Systems, Laredo, TX.

Kock, N., 2017. Structural equation modeling with factors and composites: a comparison of four methods. Int. J. e-Collaboration 13 (1), 1-9.

Krishnan, R., Martin, X., Noorderhaven, N.G., 2006. When does trust matter to alliance performance? Acad. Manag. J. 49 (5), 894-917.

Lu, Q., Goh, M., de Souza, R., 2018. An empirical investigation of swift trust in humanitarian logistics operations. In: The Palgrave Handbook of Humanitarian Logistics and Supply Chain Management. Palgrave Macmillan, London, pp. 279-296.

LaValle, S., Lesser, E., Shockley, R., Hopkins, M.S., Kruschwitz, N., 2011. Big data, analytics and the path from insights to value. MIT Sloan Manag. Rev. 52 (2), 21.

Leidner, D.E., Kayworth, T., 2006. A review of culture in information systems research: toward a theory of information technology culture conflict. MIS Q. 30 (2), 357-399.

Lewis, M.W., Boyer, K.K., 2002. Factors impacting AMT implementation: an integrative and controlled study. J. Eng. Technol. Manag. 19 (2), 111-130.

Lindell, M.K., Whitney, D.J., 2001. Accounting for common method variance in crosssectional research designs. J. Appl. Psychol. 86 (1), 114-121.

Liu, H., Ke, W., Wei, K.K., Gu, J., Chen, H., 2010. The role of institutional pressures and organizational culture in the firm's intention to adopt internet-enabled supply chain management systems. J. Oper. Manag. 28 (5), 372-384.

Lucianetti, L., Jabbour, C.J.C., Gunasekaran, A., Latan, H., 2018. Contingency factors and complementary effects of adopting advanced manufacturing tools and managerial practices: effects on organizational measurement systems and firms' performance. Int. J. Prod. Econ. 200, 318-328.

Mentzer, J.T., DeWitt, W., Keebler, J.S., Min, S., Nix, N.W., Smith, C.D., Zacharia, Z.G., 2001. Defining supply chain management. J. Bus. Logist. 22 (2), 1-25.

McPherson, C.M., Sauder, M., 2013. Logics in action: managing institutional complexity in a drug court. Adm. Sci. Q. 58 (2), 165-196.

Meyerson, D., Weick, K.E., Kramer, R.M., 1996. Swift trust and temporary groups. In: Kramer, R.M., Tyler, T.R. (Eds.), Trust in Organizations: Frontiers of Theory and Research. Sage Publications, California, pp. 166-195.

Morgan, R.M., Hunt, S.D., 1994. The commitment-trust theory of relationship marketing. J. Market. 58 (July), 20-38.

Moshtari, M., 2016. Inter-organizational fit, relationship management capability, and collaborative performance within a humanitarian setting. Prod. Oper. Manag. 25 (9), 1542-1557.

Muthén, B., 1984. A general structural equation model with dichotomous, ordered categorical, and continuous latent variable indicators. Psychometrika 49 (1), 115-132.

Muthén, B.O., 1994. Multilevel covariance structure analysis. Socio. Methods Res. 22 (3), $376-398$.

Nelson, A., Sigal, I., Zambrano, D., 2010. Media, Information Systems and Communities: Lessons from Haiti. In: John, S., James, L. (Eds.), Knight Foundation.

Netemeyer, R.G., Johnston, M.W., Burton, S., 1990. Analysis of role conflict and role ambiguity in a structural equations framework. J. Appl. Psychol. 75 (2), 148-157.

OCHA - United Nations, 2016. Office for the Coordination of Humanitarian Affairs. organigramme of the civil-military co-ordination section. https://www.unocha.org/ sites/dms/Documents/CMCS\%20organigramme\%20-\%20Nov2016.pdf.
Oloruntoba, R., 2010. An analysis of the Cyclone Larry emergency relief chain: some key success factors. Int. J. Prod. Econ. 126 (1), 85-101.

Oloruntoba, R., Hossain, G.F., Wagner, B., 2016. Theory in humanitarian operations research. Ann. Oper. Res. 1-18.

Palmatier, R.W., Dant, R.P., Grewal, D., 2007. A comparative longitudinal analysis of theoretical perspectives of interorganizational relationship performance. J. Market. 71 (4), 172-194.

Papadopoulos, T., Gunasekaran, A., Dubey, R., Altay, N., Childe, S.J., Fosso-Wamba, S., 2017. The role of big data in explaining disaster resilience in supply chains for sustainability. J. Clean. Prod. 142, 1108-1118.

Peng, D.X., Lai, F., 2012. Using partial least squares in operations management research: a practical guideline and summary of past research. J. Oper. Manag. 30 (6), 467-480.

Peng, D.X., Heim, G.R., Mallick, D.N., 2014. Collaborative product development: the effect of project complexity on the use of information technology tools and new product development practices. Prod. Oper. Manag. 23 (8), 1421-1438.

Pettit, S., Beresford, A., 2009. Critical success factors in the context of humanitarian aid supply chains. Int. J. Phys. Distrib. Logist. Manag. 39 (6), 450-468.

Podsakoff, P.M., MacKenzie, S.B., Podsakoff, N.P., Lee, J.Y., 2003. The mismeasure of man (agement) and its implications for leadership research. Leader. Q. 14 (6), $615-656$.

Podsakoff, P.M., Organ, D.W., 1986. Self-reports in organizational research: problems and prospects. J. Manag. 12 (4), 531-544.

Prasad, S., Zakaria, R., Altay, N., 2016. Big data in humanitarian supply chain networks: a resource dependence perspective. Ann. Oper. Res. https://doi.org/10.1007/s10479. 016-2280-7. online.

Prasanna, S., Haavisto, I., 2018. Collaboration in humanitarian supply chains: an organizational framework. Int. J. Prod. Res. 56 (17), 5611-5625 (accepted).

Preacher, K.J., Zyphur, M.J., Zhang, Z., 2010. A general multilevel SEM framework for assessing multilevel mediation. Psychol. Methods 15 (3), 209-233.

Premkumar, G., Ramamurthy, K., Saunders, C.S., 2005. Information processing view of organizations: an exploratory examination of fit in the context of interorganizational relationships. J. Manag. Inf. Syst. 22 (1), 257-294.

Pressey, A., Tzokas, N., Winklhofer, H., 2007. Strategic purchasing and the evaluation of "problem" key supply relationships: what do key suppliers need to know? J. Bus. Ind. Market. 22 (5), 282-294.

Quinn, R.E., Rohrbaugh, J., 1983. A spatial model of effectiveness criteria: towards a competing values approach to organizational analysis. Manag. Sci. 29 (3), 363-377.

Ragini, J.R., Anand, P.R., Bhaskar, V., 2018. Big data analytics for disaster response and recovery through sentiment analysis. Int. J. Inf. Manag. 42, 13-24.

Ralston, D.A., Terpstra-Tong, J., Terpstra, R.H., Wang, X., Egri, C., 2006. Today's state-owned enterprises of China: are they dying dinosaurs or dynamic dynamos? Strat. Manag. J. 27 (9), 825-843.

Rana, N.P., Dwivedi, Y.K., 2015. Citizen's adoption of an e-government system: validating extended social cognitive theory (SCT), Gov, Inf. Q. 32 (2), 172-181.

Ravichandran, T., Lertwongsatien, C., 2005. Effect of information systems resources and capabilities on firm performance: a resource-based perspective. J. Manag. Inf. Syst. 21 (4), 237-276.

Robert, L.P., Denis, A.R., Hung, Y.T.C., 2009. Individual swift trust and knowledge-based trust in face-to-face and virtual team members. J. Manag. Inf. Syst. 26 (2), 241-279.

Rodon, J., Serrano, J.F.M., Gimenez, C., 2012. Managing cultural conflicts for effective humanitarian aid. Int. J. Prod. Econ. 139 (2), 366-376.

Rosenthal, R., Rosnow, R.L., 1991. Essentials of Behavioral Research: Methods and Data Analysis. McGraw-Hill Humanities Social.

Rousseau, D.M., Sitkin, S.B., Burt, R.S., Camerer, C., 1998. Not so different after all: a cross-discipline view of trust. Acad. Manag. Rev. 23 (3), 393-404.

Ruppel, C.P., Harrington, S.J., 2001. Sharing knowledge through intranets: a study of organizational culture and intranet implementation. IEEE Trans. Prof. Commun. 44 (1), 37-52.

Sarstedt, M., Hair, J.F., Ringle, C.M., Thiele, K.O., Gudergan, S.P., 2016. Estimation issues with PLS and CBSEM: where the bias lies!. J. Bus. Res. 69 (10), 3998-4010.

Shortell, S.M., Zajac, E.J., 1990. Perceptual and archival measures of Miles and Snow's strategic types: a comprehensive assessment of reliability and validity. Acad. Manag. J. 33 (4), 817-832.

Shrout, P.E., Fleiss, J.L., 1979. Intraclass correlations: uses in assessing rater reliability. Psychol. Bull. 86 (2), 420-428.

Simatupang, T.M., Sridharan, R., 2002. The collaborative supply chain. Int. J. Logist. Manag. 13 (1), 15-30.

Singh, J.P., Dwivedi, Y.K., Rana, N.P., Kumar, A., Kapoor, K.K., 2017. Event classification and location prediction from tweets during disasters. Ann. Oper. Res. 1-21.

Smets, M., Morris, T.I.M., Greenwood, R., 2012. From practice to field: a multilevel model of practice-driven institutional change. Acad. Manag. J. 55 (4), 877-904.

Smith, K.G., Grimm, C.M., Gannon, M.J., Chen, M.J., 1991. Organizational information processing, competitive responses, and performance in the US domestic airline industry. Acad. Manag. J. 34 (1), 60-85.

Srinivasan, R., Swink, M., 2015. Leveraging supply chain integration through planning comprehensiveness: an organizational information processing theory perspective. Decis. Sci. J. 46 (5), 823-861.

Srinivasan, R., Swink, M., 2018. An investigation of visibility and flexibility as complements to supply chain analytics: an organizational information processing theory perspective. Prod. Oper. Manag. 27 (10), 1849-1867.

Tatham, P., Rietjens, S.B., 2016. Integrated disaster relief logistics: a stepping stone towards viable civil-military networks? Disasters 40 (1), 7-25.

Tatham, P., Kovács, G., 2010. The application of "swift trust" to humanitarian logistics. Int. J. Prod. Econ. 126 (1), 35-45.

Tenenhaus, M., Vinzi, V.E., Chatelin, Y.M., Lauro, C., 2005. PLS path modeling. Comput. Stat. Data Anal, 48 (1), 159-205. 
Thompson, J.D., 1967. Organizations in Action. McGraw-Hill Book Co., New York.

Tushman, M.L., Nadler, D.A., 1978. Information processing as an integrating concept in organizational design. Acad. Manag. Rev. 3 (3), 613-624.

Vaara, E., Tienari, J., 2011. On the narrative construction of multinational corporations: an antenarrative analysis of legitimation and resistance in a cross-border merger. Organ. Sci. 22 (2), 370-390.

Waller, M.A., Fawcett, S.E., 2013. Data science, predictive analytics, and big data: a revolution that will transform supply chain design and management. J. Bus. Logist. 34 (2), 77-84.

Wang, G., Gunasekaran, A., Ngai, E.W., Papadopoulos, T., 2016. Big data analytics in logistics and supply chain management: certain investigations for research and applications. Int. J. Prod. Econ. 176, 98-110.
Wentz, L., 2006. Information and communication technologies for civil-military coordination in disaster relief and stabilization and reconstruction. In: Defense and Technology Paper. Center for Technology and National Security Policy. National Defense University.

Wry, T., Lounsbury, M., Jennings, P.D., 2014. Hybrid vigor: securing venture capital by spanning categories in nanotechnology. Acad. Manag. J. 57 (5), 1309-1333.

Yates, D., Paquette, S., 2011. Emergency knowledge management and social media technologies: a case study of the 2010 Haitian earthquake. Int. J. Inf. Manag. 31 (1), 6-13.

Zhu, S., Song, J., Hazen, B.T., Lee, K., Cegielski, C., 2018. How supply chain analytics enables operational supply chain transparency: an organizational information processing theory perspective. Int. J. Phys. Distrib. Logist. Manag. 48 (1), 47-68. 